Research Article

\title{
Research of Thermal Effect of Cable-Stayed Bridge with a Separated Side-Box Steel-Concrete Composite Girder under Solar Radiation
}

\author{
Han-hao Zhang $\left(\mathbb{D}\right.$, Pei-zhi Wang $\left(\mathbb{D}\right.$, Shuanhai He $\mathbb{D}$, Yuan Li $\mathbb{D}^{D}$, Ke-fan Chen $(\mathbb{D}$, \\ and Nan-nan Sun $(\mathbb{D}$
}

School of Highway, Chang'an University, Xi'an 710064, China

Correspondence should be addressed to Han-hao Zhang; 2018021030@chd.edu.cn

Received 15 September 2020; Revised 9 March 2021; Accepted 20 March 2021; Published 7 April 2021

Academic Editor: Hui Yao

Copyright (c) 2021 Han-hao Zhang et al. This is an open access article distributed under the Creative Commons Attribution License, which permits unrestricted use, distribution, and reproduction in any medium, provided the original work is properly cited.

\begin{abstract}
At present, there are few studies on the thermal effect of solar radiation on a separated double-sided box steel-concrete composite girder cable-stayed bridge. In this paper, the beam element and mixed element models are combined with the theory of transient heat transfer analysis and meteorology; this approach is adopted to carry out a thermodynamic analysis of a related bridge project. The calculation results of the thermal field and structural thermodynamic analysis of bridge sections show that, in terms of a separated double-sided box steel-concrete composite girder cable-stayed bridge, the thermal field distributions of the main girder and the pylons are extremely complex under conditions of solar radiation. Therefore, the real thermal field cannot be accurately described as a one-dimensional temperature gradient. The traditional beam element model cannot accurately simulate the temperature effect, and it will underestimate its thermal effect. The calculated temperature stress values of the mixed element model are quite different from those of the of beam element model. The mixed element model can precisely reflect the local thermal effect of each component in this system under solar radiation. Compared with the calculation results of the beam element model, the maximum temperature stress of the bridge deck in each section of the main girder is generally $20 \%$ larger; the maximum temperature stress levels of the steel-beam top and bottom plates are $14.7 \mathrm{MPa}$ and $15.9 \mathrm{MPa}$ larger, respectively. The maximum shear stress of the steel-concrete interface is $0.2 \mathrm{MPa}$ larger. The research results of the temperature effect calculated by the mixed element have an important guiding significance for the design and maintenance of bridges.
\end{abstract}

\section{Introduction}

Cable-stayed bridges with steel-concrete composite girders have been widely used in modern long span bridge design and construction $[1,2]$. The separated side-box cross section has multiple advantages, such as excellent stability during construction and convenience in terms of setting up the steel anchor box and also maintaining it [1].

In recent years, some scholars have researched the distribution of a thermal field and conducted various analyses of the thermal effect created by solar radiation. Jiang et al. [3] fitted two positive temperature gradient distribution modes and a negative temperature gradient distribution mode of the main beam section of a steel-concrete composite girder cable-stayed bridge with a small proportion of cantilever length and beam height. Mosavi et al. [4] conducted all-weather field tests regarding the temperature (ambient temperature and main girder section temperature) and structural natural frequency of a two-span steel-concrete composite girder in the summer. The relationship between the measured frequency and the measured temperature of the bridge was analyzed through field observation data, and the influence of environmental temperature variation on the modal characteristics of the steel-concrete composite beam bridge was studied. Based on elastic theory, Zhou et al. [5] deduced the calculation formulas of the shear stress, relative slip deformation, and bending deformation curvature of steel-concrete composite beams under different temperature gradient modes. The thermal effect on an I-beam under a specified temperature gradient was analyzed 
by the derived formulas. Wang [6] analyzed the thermal field of the main girders, main pylons, and stay cables of a doublebeam steel-concrete composite cable-stayed bridge under solar radiation according to the basic theories of meteorology and heat transfer theory and fitted the maximum temperature gradient mode of each component section. Then, based on the fitted temperature gradient mode of each component, the beam element model was adopted to analyze the thermal effect on bridges under solar radiation. Zhu and Meng [7] proposed a three-dimensional shading algorithm, which can automatically calculate the thermal field of a bridge under solar radiation, taking into consideration the mutual shading effect between components in the finite element model. Then, taking a steel-concrete composite girder cable-stayed bridge as an example, the temperature effect was analyzed considering the shading effect. The calculation results show that the temperature effect is greatly affected by the mutual shading effect between the components because the temperature value and temperature stress of the occluded section are significantly lower than those of surrounding part. The characteristics of a cable-stayed bridge with separated side-box steel-concrete composite girders under conditions of solar radiation are listed as follows: the complex distribution of the thermal field of the cross section, relatively high local stress in the steel-beam web, which is easily exposed to the solar radiation, misdistribution of thermal stress in the flat bridge deck, and structural thermal stress that is influenced dramatically by the slip effect $[8,9]$.

However, too little research has been devoted to the thermal effect of solar radiation on a cable-stay bridge with separated side-box steel-concrete composite girders $[3-5,7,9,10]$. Although previous scholars have simplified the thermal field into a pattern of unidimensional distribution by means of the traditional beam element method $[6,11]$, this method cannot properly reflect the local temperature variations or reveal the features of the thermal field and the mechanical effect. Significant differences exist between the calculation results of the thermal effect of the beam element model and the mixed element model $[9,12,13]$. Hence, it is important to conduct research using the mixed elements' model on the thermal effect of solar radiation on a cable-stayed bridge with separated side-box steel-concrete composite girders.

In this passage, the sequential thermal-mechanical coupling was adopted to accurately analyze the thermal effect of solar radiation on a cable-stayed bridge with separated side-box steel-concrete composite girders. According to the heat transferring theory and also to meteorological data, the transient thermal field was applied to the crosssection analysis. Then, the data of the thermal field were imported into finite element models for mechanical analysis, which took into account the influence of the environment.

\section{Theories and Methods}

The thermal effect analysis of a bridge under solar radiation which is presented in this paper consisted of two parts: heat transfer theory and mechanical behavior under thermal loads. The detailed relevant theories and simulation method are shown below.

2.1. Heat Transfer Analysis. Studies usually neglect the temperature differences along the longitudinal direction of a bridge $[1,14]$. A section can be used to analyze the temperature distribution of the bridge. The thermal environment is shown in Figure 1.

2.2. Heat Conduction Theory. The analysis of the thermal field of a bridge under solar radiation should be regarded as transience, which can be described as a two-dimensional transient thermal conductivity differential $[13,14]$ :

$$
\alpha\left(\frac{\partial^{2} T}{\partial x^{2}}+\frac{\partial^{2} T}{\partial y^{2}}\right)=\frac{\partial T}{\partial t}
$$

where $T=T(x, y), x$ and $y$ are the coordinates of a cartesian coordinate system, $t$ is time, and $\alpha$ is the thermal diffusivity of material.

The heat exchange at the outer surface boundary includes the sum of solar radiation $q_{s}$, convective heat transfer $q_{c}$, and long wave radiation $q_{r}$, as shown in equation (2). The thermal boundary condition is a mixed boundary condition including the second and third boundary conditions, which can be written as $[13,14]$

$$
\begin{aligned}
& \lambda\left(\frac{\partial T}{\partial n}\right)_{\Gamma}=q_{s}+q_{c}+q_{r}, \\
& \lambda\left(\frac{\partial T}{\partial n}\right)_{\Gamma}=h\left(T_{a}-T\right)+q_{s}-q_{r a}
\end{aligned}
$$

where $\lambda$ is the thermal conductivity of the material, $\partial T / \partial n$ is the temperature variation rate along the normal direction of the boundary $\Gamma, h$ is the general convective heat transfer coefficient, $T_{a}$ is the atmospheric temperature of the environment, $T$ is the surface temperature of the structure which contacts the air, $q_{s}$ is the heat flux of shortwave radiation, which is actually absorbed by the structural surface, and $q_{r a}$ is a subitem of $q_{r}$.

2.3. Shortwave Radiation. The shortwave actually absorbed by the surface structure includes 3 items: direct solar radiation, sky diffusion, and ground reflection. Thus, the heat flux of shortwave radiation is actually absorbed by the structural surface, $q_{s}$, which can be given as follows $[13,15]$ :

$$
\begin{aligned}
q_{s}= & A_{s}\left[I_{D} \cos \phi+\frac{1+\sin \beta_{n}}{2} I_{d H}\right. \\
& \left.+\frac{1-\sin \beta_{n}}{2} r_{e}\left(I_{D} \sin \beta_{s}+I_{d H}\right)\right],
\end{aligned}
$$

where $A_{s}$ is the absorption factor of the solar radiation, $I_{D}$ is the solar direct radiative intensity, calculated as $I_{D}=0.9^{t_{u}} k_{a} m I_{0}$ (where $t_{u}$ is the atmospheric turbidity coefficient, $k_{a}$ is the relative barometric pressure, $m$ is the 


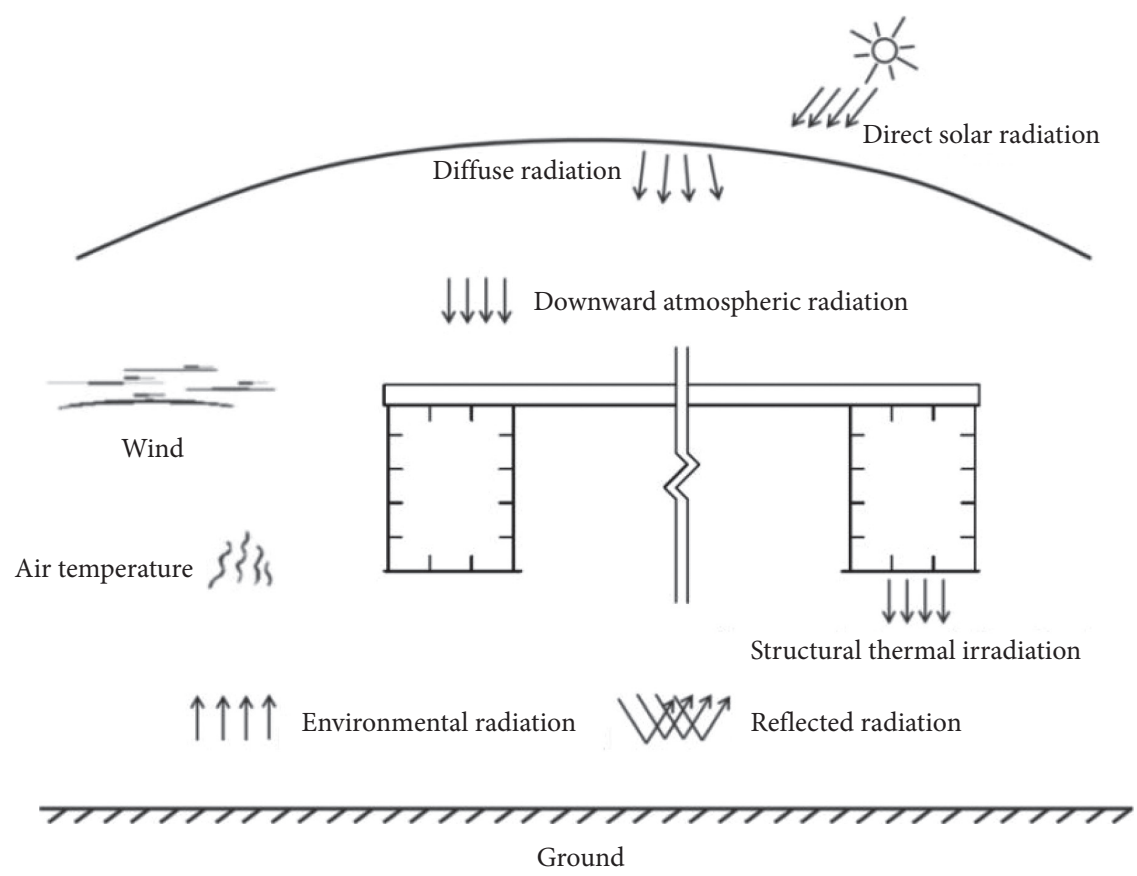

FIgURe 1: Thermal environments of a bridge.

optical air mass, and $I_{O}$ is the solar constant), $\phi$ is the solar incident angle, $\beta_{n}$ is the angle between the exterior normal area of the structure surface and the ground plane, $\beta_{s}$ is the sun elevation angle, $I_{d H}$ is the scattering intensity of horizontal plane, calculated as $I_{d H}=\left(\begin{array}{lll}0.271 & I_{0}-0.294\end{array}\right.$ $\left.I_{D}\right) \cdot \sin \beta_{s}$, and $r_{e}$ is the reflectivity of the shortwave of the ground.

2.4. Longwave Radiation. Based on the general effect of the combination of emitted and absorbed radiation, the influx indicates longwave radiation passing from the atmospheric environment into the structural interior through the structural surface, as given by equations (5)-(7) $[13,15]$ :

$$
\begin{aligned}
& q_{r}=h_{r}\left(T_{a}-T\right)-q_{r a}, \\
& h_{r}=\varepsilon C_{0}\left(546+T_{a}+T\right)\left[\left(273+T_{a}\right)^{2}+(273+T)^{2}\right], \\
& q_{r a}=\frac{1+\sin \beta_{n}}{2}\left(1-\varepsilon_{a}\right) \varepsilon C_{0}\left(273+T_{a}\right)^{4},
\end{aligned}
$$

where $h_{r}$ is the radiant heat exchange coefficient; $\varepsilon$ is the material emissivity, $C_{0}$ is the disposal of Boltzmann's constant, and $T_{a}$ can be taken as the average atmospheric temperature.

2.5. General Convective Heat Transfer Coefficient. The general convective heat transfer coefficient represents the comprehensive effect of convection and radiation. When the wind speed is lower than $5 \mathrm{~m} / \mathrm{s}$ above the structure's surface, it can be written as follows [15-17]:

$$
h=h_{r}+h_{c}=h_{r}+2.6\left(\sqrt[4]{\left|T_{a}-T\right|}+1.54 v\right),
$$

where $h$ is the general convective heat transfer coefficient, $h_{c}$ is the heat exchange coefficient, $v$ is the wind speed above the structure's surface, and $T_{a}$ can be taken as the average atmospheric temperature.

2.6. The Temperature of Environment. Daily temperature changes can be simplified as a sine curve to describe the environmental temperature variation $[15,16]$ :

$$
\begin{aligned}
T_{a}(t)= & \frac{1}{2}\left(T_{a, \max }+T_{a, \min }\right) \\
& +\frac{1}{2}\left(T_{a, \max }-T_{a, \min }\right) \sin \frac{(t-3) \pi}{12},
\end{aligned}
$$

where $T_{a, \max }$ and $T_{a, \min }$ are the maximum temperature and minimum temperature, respectively.

\section{Simulation Method}

3.1. Thermal Field Analysis. The thermal field of the cross section is usually regarded as having a two-dimensional distribution of temperature $[1,14]$, which is regarded as a plane problem. To analyze the thermal field of a cross section, it is necessary to model the components precisely in the finite element model. The thermal boundary condition, the geometric dimensions of the bridge components, and the thermodynamic parameters of the material need to be modelled accurately [7]. According to thermodynamics, the air inside the box girder should be regarded as a finite element mesh, and it should be included in the numerical calculation, since the closed atmosphere inside the box 
girder can significantly impact the temperature distribution [18].

The beam element model uses the temperature gradient as the traditional method. This model is fitted with the average temperature of each position along the height of the section which corresponds to the time when the cross section reaches the highest temperature; this is adopted in the thermal effect analysis. In the mixed element model, the two-dimensional thermal field of the cross section can be directly imported as the analysis thermal effect.

3.2. The Mechanical Behavior Analysis. The mechanical model can be built as a three-dimensional beam element model or a mixed element model. However, the beam element model cannot take temperature inhomogeneity into account; it can only consider the unidimensional vertical temperature distribution of the cross section [1]. The unidimensional temperature gradient is applied to the both ends of the element to calculate the temperature stress [19]. The mixed element model can fully consider the temperature inhomogeneity of the cross section; it can calculate the value of the thermal effect caused by local temperature variations. The rise and reduction of temperature of each node within the mixed element model are used to calculate the value of the thermal stress of each element. The initial stress field (displacement field) and thermal field should be analyzed before the analysis of the mechanical behavior [7]:

3.2.1. Initial Stress Field (Displacement Field). The calculation of thermal loading was based on the initial stress field (displacement field). Before analyzing the thermal field, the existing stress was obtained by the calculation of the initial stress field (displacement field) of the cable-stayed bridge after it underwent each construction stage.

3.2.2. Initial Thermal Field. In previous studies, the temperature at midnight ( 0 o'clock) has typically been used as the initial temperature of the bridge $[6,7]$. However, according to the existing bridge monitoring data, the temperature of the bridge structure (especially the steelconcrete composite girder) reaches its minimum during 5 to 7 o'clock in the morning, falling to a temperature that is relatively close to the atmospheric temperature $[7,18,20]$. Hence, in this paper, the time of the initial thermal field was set as 5 o'clock, and the time of the heat transfer analysis of both the cross section and the overall structural mechanics analysis was set as 5 o'clock.

\section{Case Study}

4.1. Overview. In this passage, the model was set up as a three-span, double pylon, double cable plane, and steelconcrete composite girder cable-stayed bridge, with a variation diamond type of pylon with a height of $123 \mathrm{~m}$ and separated side-box steel-concrete composite girders. The stander span is composed of $(30+95+305+110+30) \mathrm{m}$. The steel boxes and concrete bridge deck are connected by shear studs. The stay cables are parallel steel cables; there are a total of 96 cables with 5 specifications: PES7-73 (Cable 1\# 3\#), PES7-91 (Cable 4\# 5\#), PES7-109 (Cable 6\# 7\#), PES7-139 (Cable 8\# 9\#), and PES7-139 (Cable 10\# 12\#). The general layout of the cable-stayed bridge and the horizontal crosssection graph are shown in Figure 2. The material mechanics parameters of the main components are shown in Table 1 $[15,16,18,20-22]$.

The cable-stayed bridge is located at longitude $116.41^{\circ}$ East and latitude $23.24^{\circ}$ North, and the angle between the axial direction of the bridge and due north is $12.3^{\circ}$. The hottest month of the year in the local area is August (the average daily maximum temperature is $35^{\circ} \mathrm{C}$ ); the coldest month of the year is February (the average daily maximum temperature is $18^{\circ} \mathrm{C}$ ).

4.2. Model of Heat Transfer Analysis. The transient heat transfer analysis model was analyzed as a plane plate element, and the element models of the girders, pylons, and stay cable are shown in Figure 3. The maximum and minimum thermal effects occur in summer and winter, respectively $[1,7]$. Thus, this paper focuses only on the thermal effects in summer and winter. The parameters of the element are shown in Table 1. According to equation (3), the total daily solar radiation at the horizontal plane of summer and winter are $25 \mathrm{MJ} / \mathrm{m}^{2}$ and $17.3 \mathrm{MJ} / \mathrm{m}^{2}$, respectively. Based on the observation of the local meteorological station, the total daily solar radiation at the horizontal plane of summer and winter are $18.7 \mathrm{MJ} / \mathrm{m}^{2}$ and $11.2 \mathrm{MJ} / \mathrm{m}^{2}$, respectively [25]. The reason for the differences is that the actual local meteorological conditions deviated from the assumption made in equation (3).

This paper studies the variation law and characteristics of the temperature effect solar radiation on a separated double-sided box steel-concrete composite girder cable-stayed bridge; however, because the meteorological monitoring system was not installed on the bridge, the hourly solar radiation data at the bridge site cannot be obtained. Therefore, this paper referred to the relevant research [6] and reduced the calculated value of the theoretical formula according to the total amount of horizontal daily solar radiation recorded by local meteorological stations. Thus, the results from equation (3) were corrected as multiplied by $0.75(18.7 / 25)$ and 0.65 (11.2/17.3) [6], and the corrected heat flux intensity on the bridge surface (solar radiation intensity) is shown in Figure 4 . The temperature variation of the atmosphere is shown in Figure 5.

The heat transfer analysis model needs to define the heat flux intensity and heat exchange boundary on the outer surface of the component. The surface heat flux intensity is defined to simulate the total radiation absorbed by the cross-section surface, and the heat exchange boundary is defined to simulate the convective and radiative heat exchange between the cross-section surface and the atmosphere. 


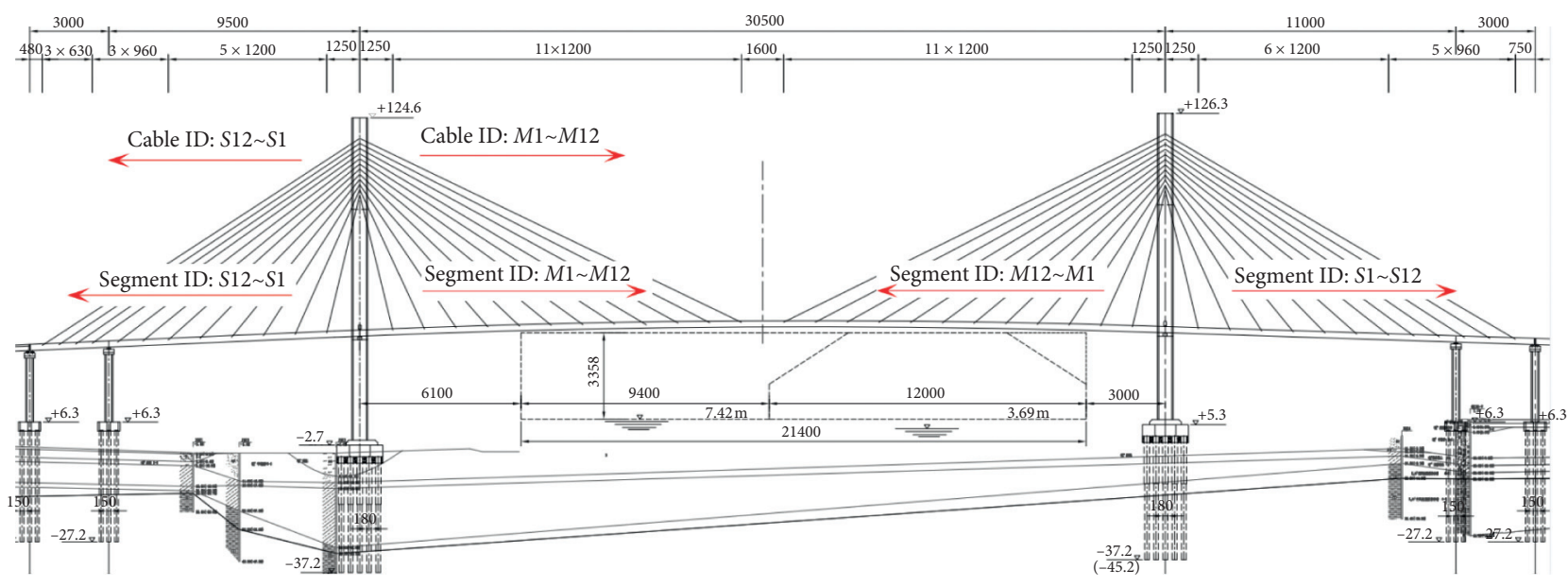

(a)

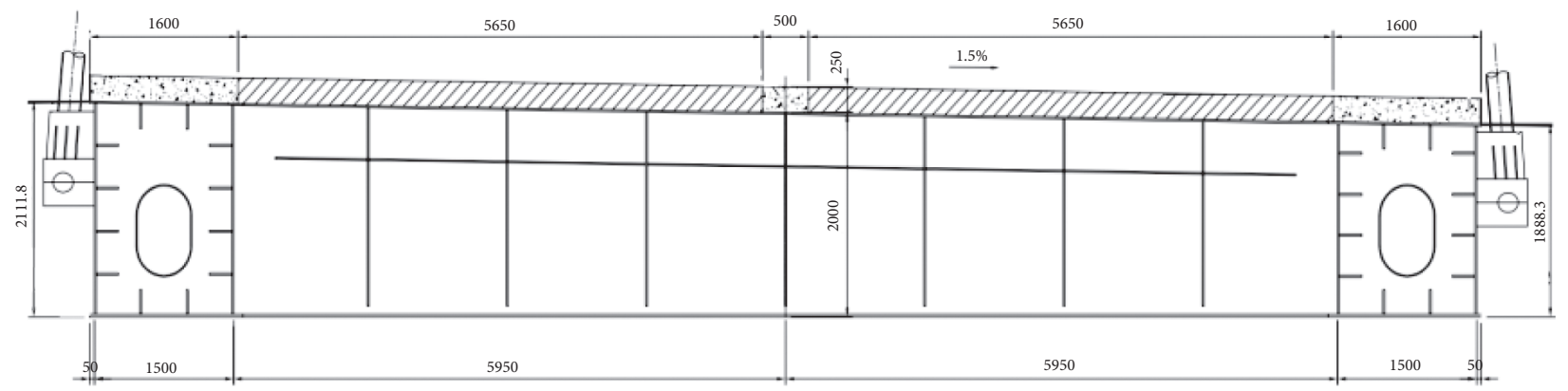

(b)

Figure 2: General layout and the cross section of the girder. (a) General layout (cm). (b) Cross section of the main girder (cm).

TABLE 1: Material mechanics parameters.

\begin{tabular}{lcccccc}
\hline Parameters & Steel & Asphalt & Concrete & Air & HDPE & Steel wire of stay cable \\
\hline Elastic modulus $(\mathrm{MPa})$ & 206000 & - & 36000 & - & - & 205000 \\
Poisson ration & 0.3 & - & 0.2 & - & - & 0.3 \\
Density $\left(\mathrm{kg} / \mathrm{m}^{3}\right)$ & 7850 & 2400 & 2600 & - & - & 7850 \\
Thermal expansion coefficient $\left(1 /{ }^{\circ} \mathrm{C}\right)$ & $1.2 e-05$ & - & $1.0 \mathrm{e}-05$ & - & - & - \\
Solar radiation absorptivity & 0.75 & 0.9 & 0.65 & - & 0.63 & - \\
Solar radiation emissivity & 0.8 & 0.92 & 0.88 & - & 0.93 & - \\
Thermal conductivity $\mathrm{W} /\left(\mathrm{m} \cdot{ }^{\circ} \mathrm{C}\right)$ & 60 & 1.8 & 2.71 & 0.026 & 0.42 & 508 \\
Specific heart capacity $\left(\mathrm{J} / \mathrm{kg} /{ }^{\circ} \mathrm{C}\right)$ & 460 & 1075 & 960 & 1.007 & 2250 & \\
\hline
\end{tabular}

Note: Poisson ratio, solar radiation absorptivity, and solar radiation emissivity are dimensionless parameters. The material properties in the table are derived from $[23,24]$.

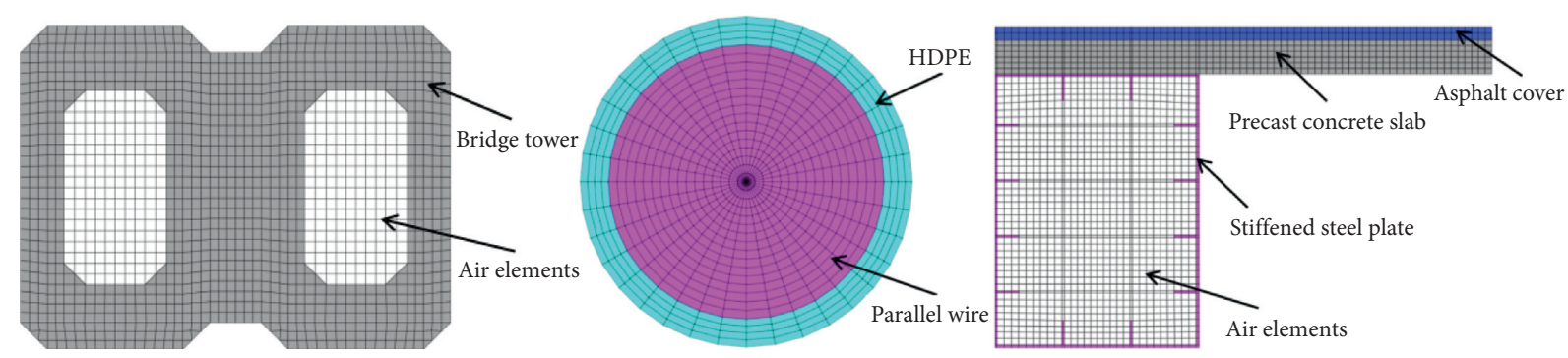

Figure 3: The heat transfer analysis in the finite element model. 


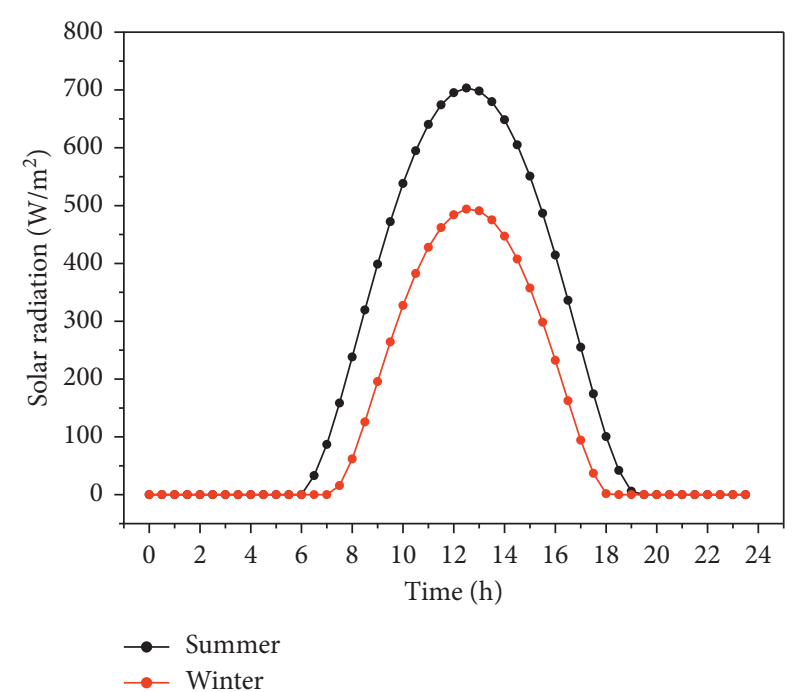

FIGURE 4: Seasonal variation of solar radiation intensity on the bridge surface.

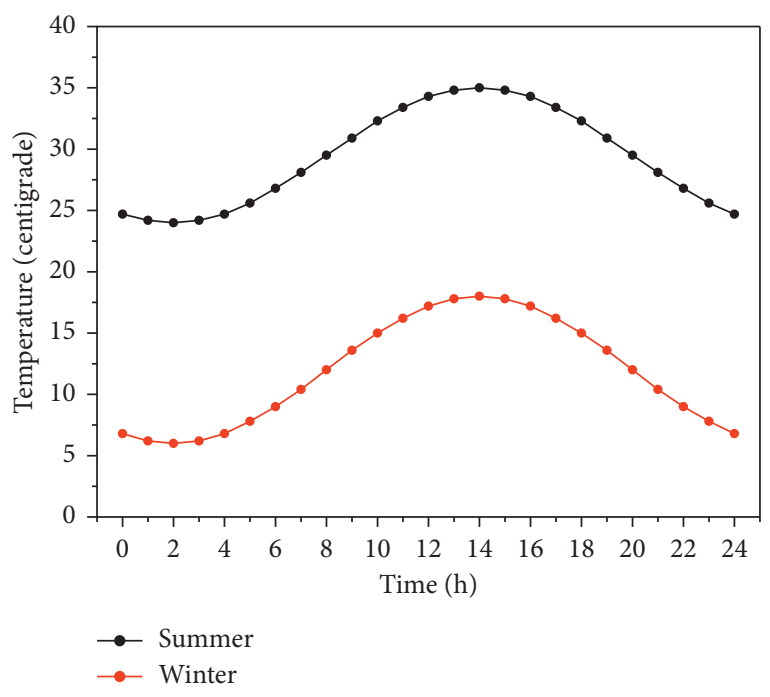

FIgURE 5: The temperature variation of the atmosphere.

\section{Model of Mechanical Analysis}

5.1. Beam Element Model. The main girder and pylon were modelled by a space beam element, and the stay cable was modelled by a spatial truss element. The schematic diagram of the finite element model (beam element) of the main bridge is shown in Figure 6. The model adopts the linear elastic material constitutive relationship, and the entire bridge is divided into 898 beam elements and 96 truss elements.

5.2. Mixed Element Model. The main components include stay cables, pylons, and main beams. The stay cables were simulated by a truss element; each stay cable is a truss element. The segments of pylons and main beams were divided according to the actual construction process. Each pylon was divided into 20 segments, and each main beam was divided into 54 segments. The mixed element model adopts a linear elastic material constitutive relationship, with 530,000 nodes and 510,000 elements. The finite element model of the main bridge is shown in Figure 7.

The three-dimensional mixed element model was set up to include the following: solid elements (pylons and bridge deck), plate elements (steel boxes), truss elements (stay cables), and interface contact elements (simulation of the interface of steel and concrete) and boundary elements (simulation of boundary conditions). The shear rigidity and the vertical rigidity of the interface contact element were $3 \mathrm{~N} / \mathrm{mm}^{2}$ and $7 \mathrm{~N} / \mathrm{mm}^{2}$, respectively [24]. The mechanical parameters of other elements are shown in Table 1. Each pylon was divided into $800-1000 \mathrm{~mm}$ tetrahedral units. The bridge deck was divided into hexahedral elements of $300 \times 300 \times 125 \mathrm{~mm}$ and $250 \times 300 \times 125 \mathrm{~mm}$ (above the steel beam). The steel longitudinal beam was divided into $300 \times 400 \mathrm{~mm}$ (web) and $300 \times 285 \mathrm{~mm}$ four-node plate elements. The steel beam was divided into $300 \times 300 \mathrm{~mm}$ (top plate and bottom plate) and $300 \times 280 \mathrm{~mm}$ (web) four-node plate elements. The interface of the steel beams and the concrete was divided into $300 \times 300 \mathrm{~mm}$ and $300 \times 285 \mathrm{~mm}$ four-node interface contact elements.

The finite element model of the bridge with a mixed element model is shown in Figure 7.

\section{Results and Discussion}

In the finite element model, the deployment of temperature observation points of the pylons and then of the main girder are shown in Figure 8, including 4 temperature observation points on the pylons and 26 temperature observation points on the main girder. The bridge deck and steel box top plate shared the temperature observation points at GT9-GT11 and GT14-GT16.

6.1. Thermal Field Analysis of Stay Cables. Five sizes of stay cables, including Cable 1\# (PES7-73), Cable 4\# (PES7-91), Cable 6\# (PES7-109), Cable 8\# (PES7-139), and Cable 10\# (PES7-163) in the midspan were selected to show the average cross-section temperatures of the stay cables in summer and winter, as shown in Figure 9. The maximum temperature of the stay cables in summer was $41.0^{\circ} \mathrm{C}$ (rising $14.5^{\circ} \mathrm{C}$ ) and in winter it was $24.3^{\circ} \mathrm{C}$ (rising $16.5^{\circ} \mathrm{C}$ ). Thus, the temperature rising behavior is basically identical with the temperature variation of the atmosphere. In addition, the temperature of the cables with a small cross section is slightly lower than the temperature of cables with a large cross section. As the cables with a small cross section have a large angle horizontal plane, the solar radiation intensity received by the cables with a small cross section is less than that of cables with a large cross section.

6.2. Thermal Field Analysis of Pylon. The temperature variations of pylons in winter and summer are shown in Figure 10. In summer, the east side of the pylon (TT3) started to heat up at 7 o'clock and reached the maximum temperature at 10 o'clock; then, the temperature tended to the ambient 


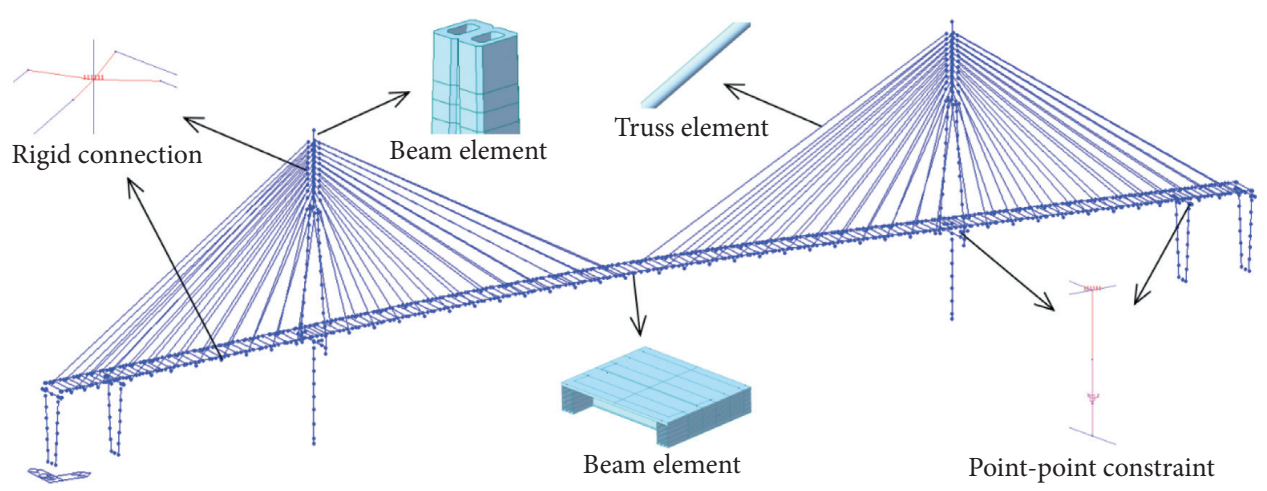

Figure 6: The finite element model with a beam element schematic diagram.

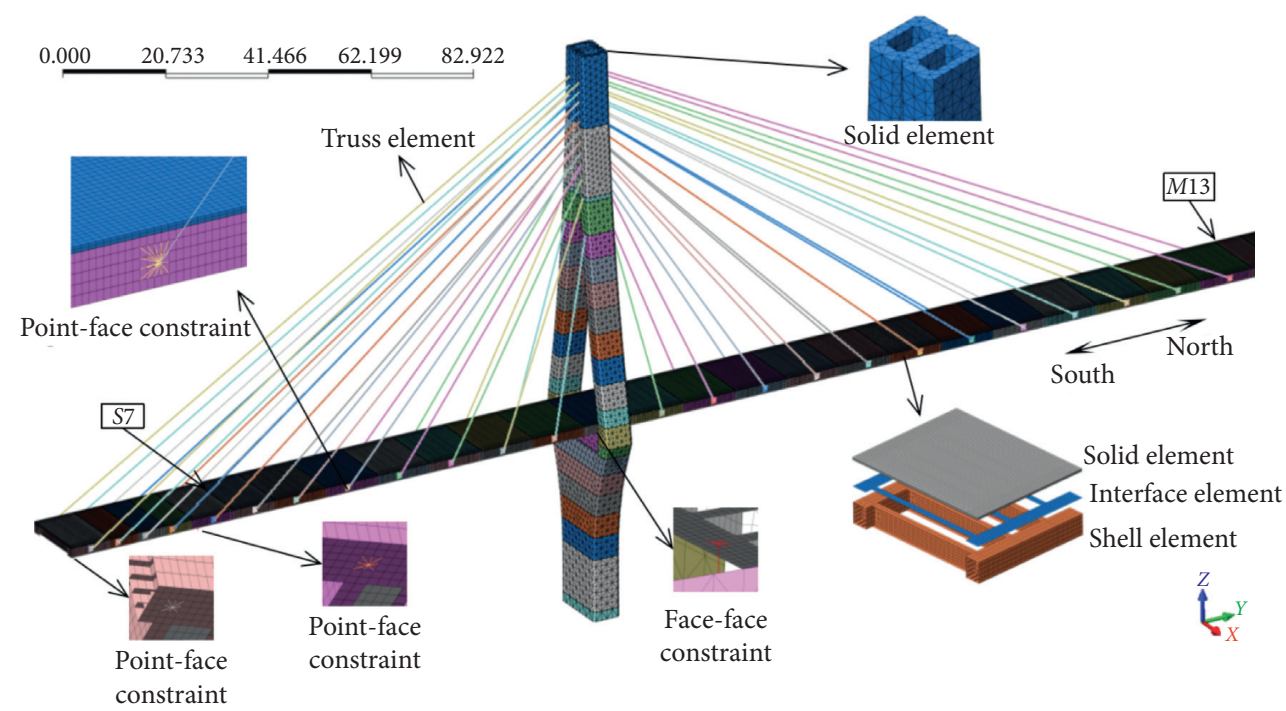

Figure 7: The finite element model with a mixed element schematic diagram.

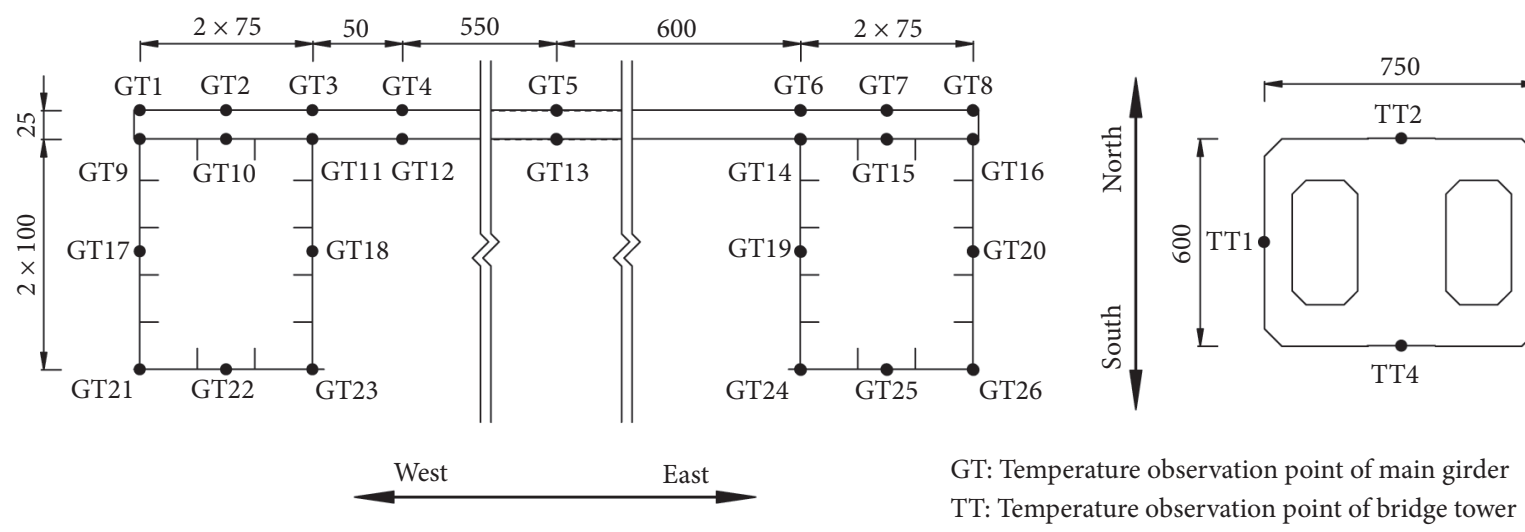

FIGURE 8: The location of temperature observation points.

temperature after noon. The temperature variation on the west side of the pylon (TT1) lagged behind that of the east side of the pylon. In winter, because of the influence from the sun azimuth variation, the north side of the pylon (TT2) started to heat up rapidly at 8 o'clock and then reached the maximum temperature at noon, and the temperature eventually fell back to the ambient temperature after 18 o'clock.
6.3. Thermal Field Analysis of Main Girder. The trend of the temperature variation of the main girder in summer is basically identical with that in winter. The temperature variations of the main girder in summer are shown in Figure 11. The temperature variation of GT4 and GT5 were identical, and the temperature variation of GT12 and GT13 were also the same, which shows that the two separated boxes have the same temperature distribution. The 


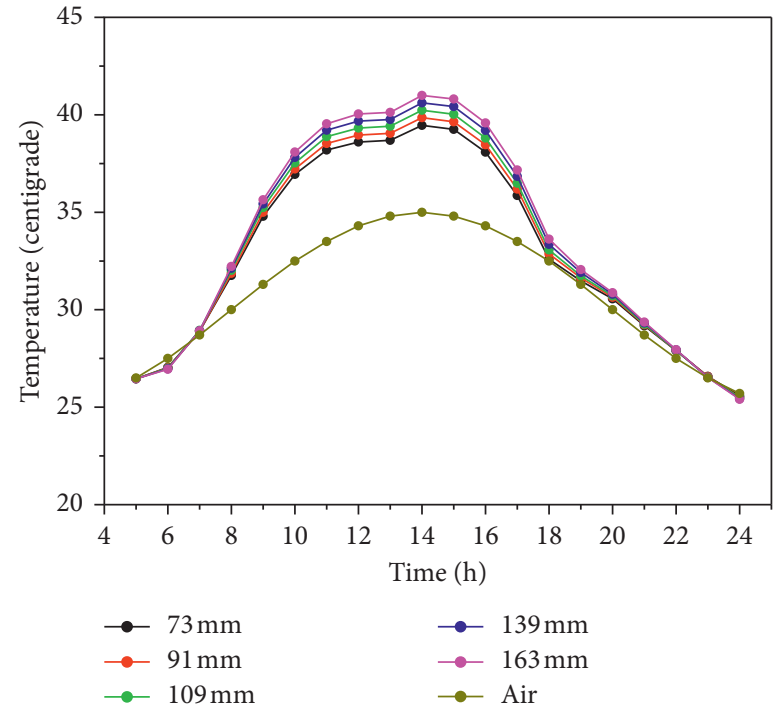

(a)

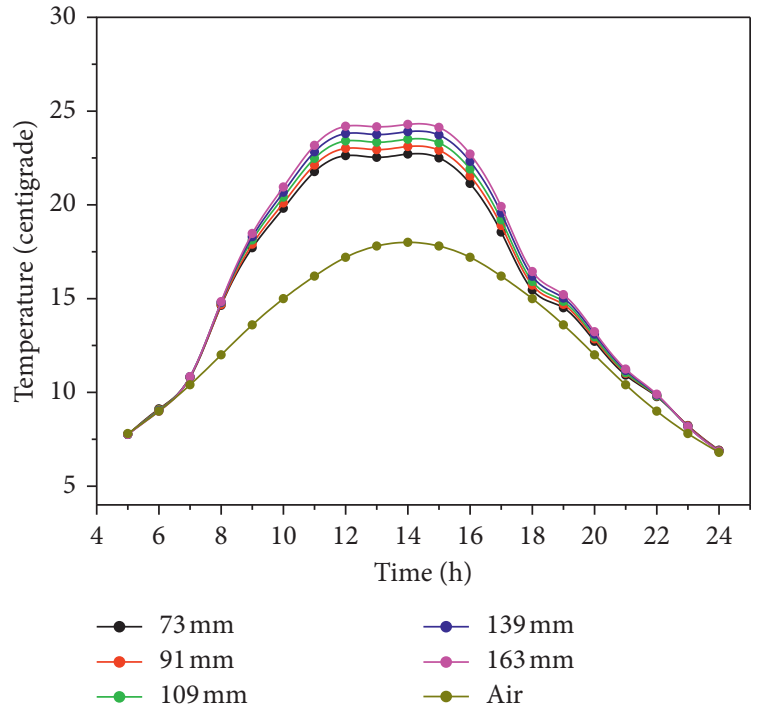

(b)

Figure 9: The temperature variation of stay cables. (a) The temperature variation of stay cables in summer. (b) The temperature variation of stay cables in winter.

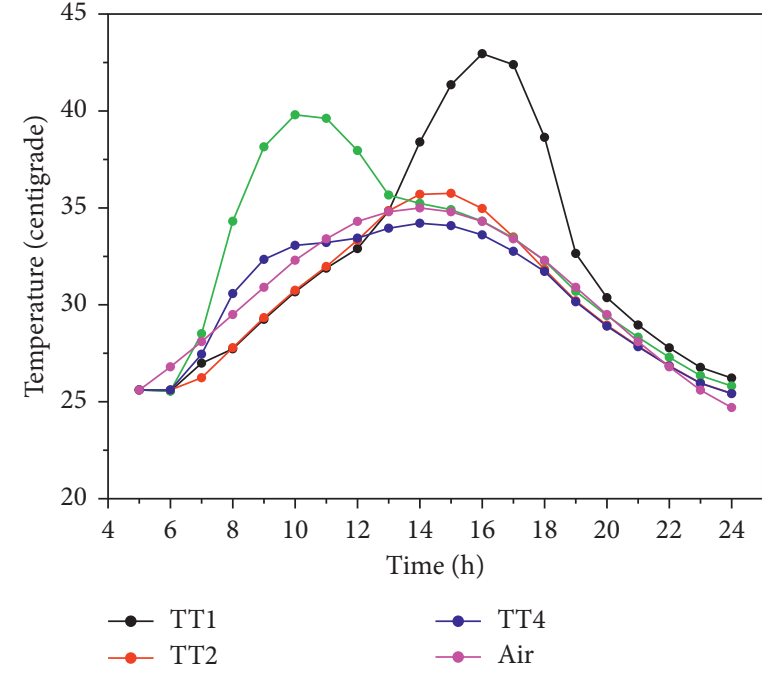

(a)

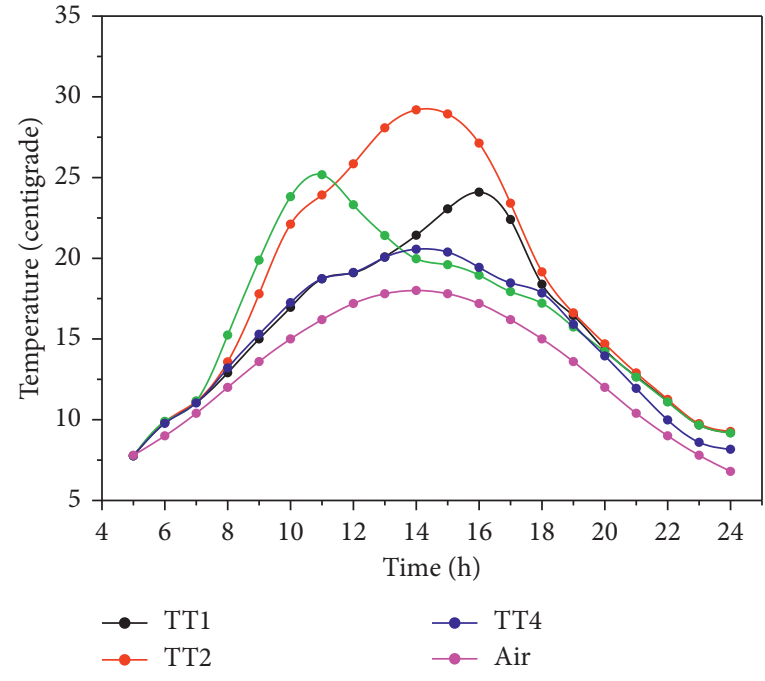

(b)

FIgURE 10: The temperature variation of cross sections of pylons. (a) The temperature variation of cross sections of pylons in summer. (b) The temperature variation of cross sections of pylons in winter.

temperatures of GT9 and GT11 (the area of the bridge deck near the web of the steel box) were lower than that of GT10 (the area right above the box), which show that the temperature distribution is influenced by the atmosphere inside the boxes. The temperature of the external web gradually decreased from the top of the steel web to the bottom (GT9GT17-GT21). The temperature of the inner web was basically similar because of the influence of solar radiation. The temperature of the bottom plate of the box gradually decreased from the outside to the inside (GT21-GT22-GT23). The temperature of the main cross section of the main girder reached the maximum at 14 o'clock. The bridge deck between the two separated steel boxes (GT4 and GT5) reached the highest temperature at $54.1^{\circ} \mathrm{C}$ (rising $28.5^{\circ} \mathrm{C}$ ). The upper edge of the bridge deck right above the steel box (GT2) reached the highest temperature at $55.4^{\circ} \mathrm{C}$ (rising $\left.29.8^{\circ} \mathrm{C}\right)$.

Based on the above analysis of the temperature of the main girder and the stay cables, it was found that they all reached the maximum temperature levels at 14 o'clock. Thus, in the beam element model, the vertical temperature gradient, fitted by the average temperature at 14 o'clock as shown in Figure 12, was adopted to analyze the thermal effect on the main girder, and the temperature at 14 o'clock 


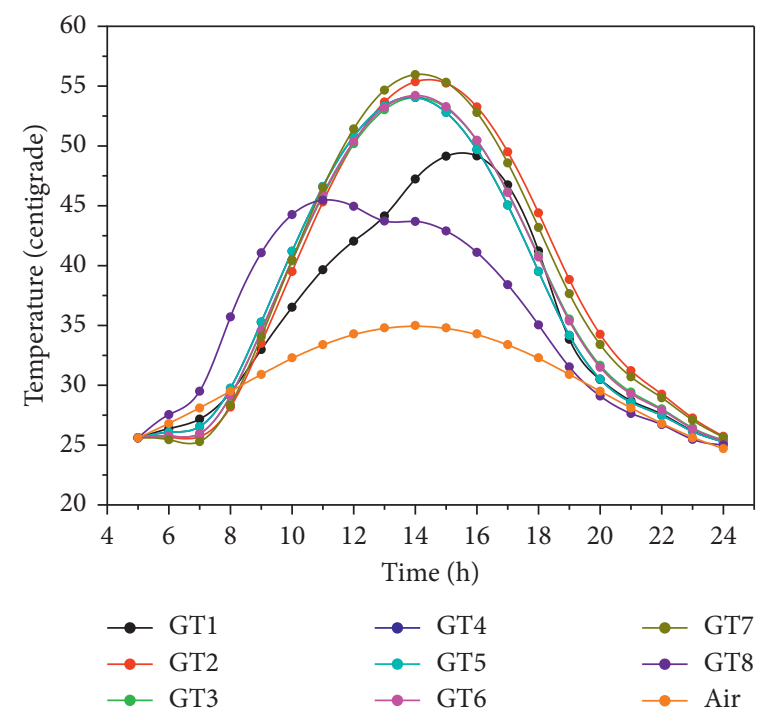

(a)

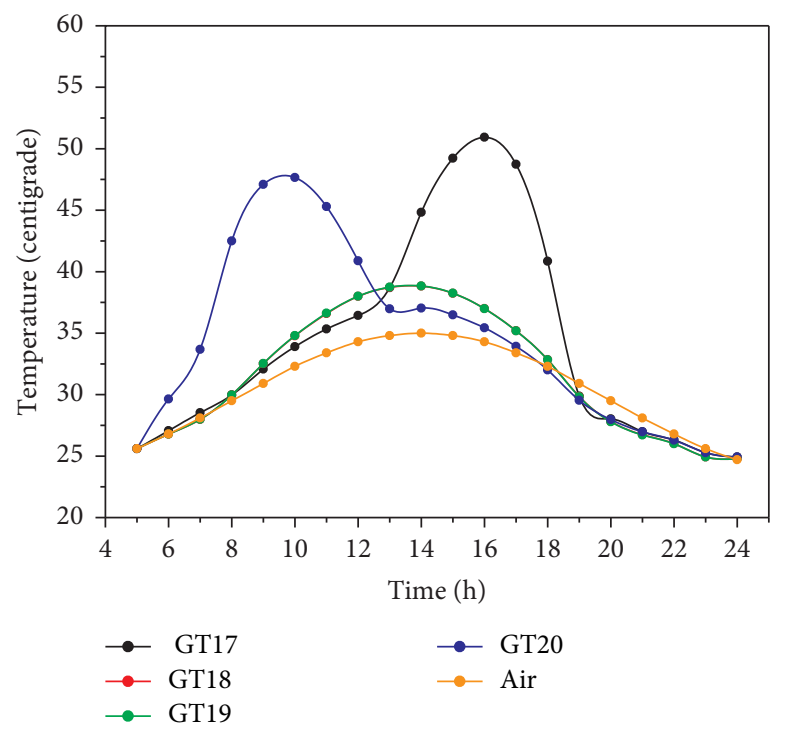

(c)

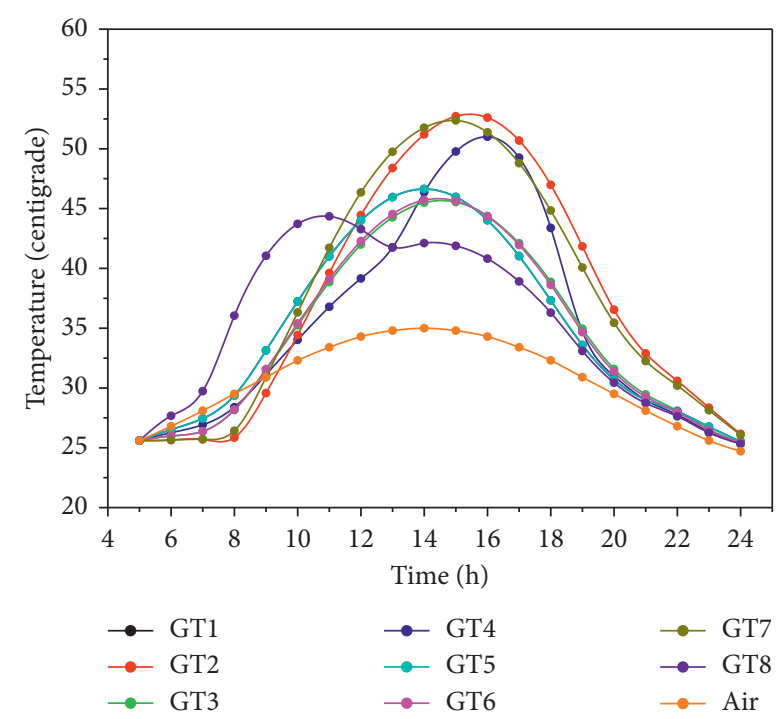

(b)

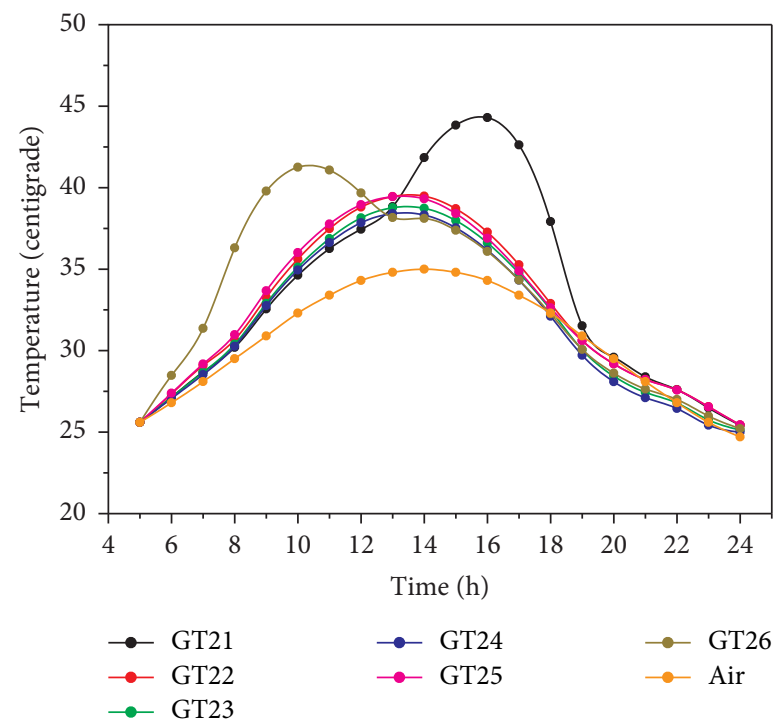

(d)

FIgURE 11: The temperature variations of the cross sections of the main girder.
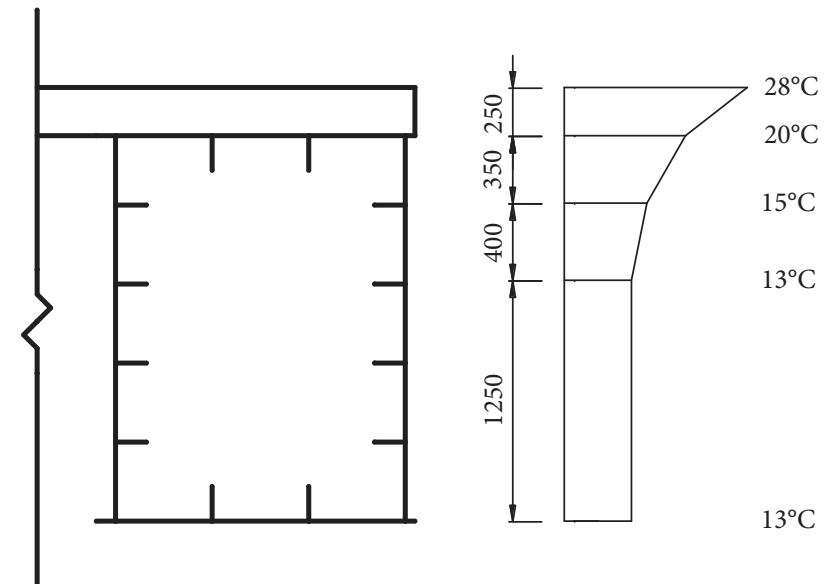

FIgURE 12: The vertical temperature gradient of the main girder. (rising $14.5^{\circ} \mathrm{C}$ in summer) was adopted in the analysis of the thermal effect on the stay cables. In the mixed element model, the temperature variation at each hour from 5 o'clock to 24 o'clock was adopted to analyze the thermal effect on the structure.

6.4. Thermal Effect of Bridge. The stress observation points of the cross section of the main girder were deployed as shown in Figure 13, including 17 stress observation points on the concrete bridge deck and 8 on each top plate and bottom plate of the steel boxes.

6.5. Stress of Bridge Deck. The average stress values of the upper edge of each section of the bridge deck (average values of DS1 DS17) are shown in Figure 14. It can be seen that each section of the bridge deck was under compression, and 


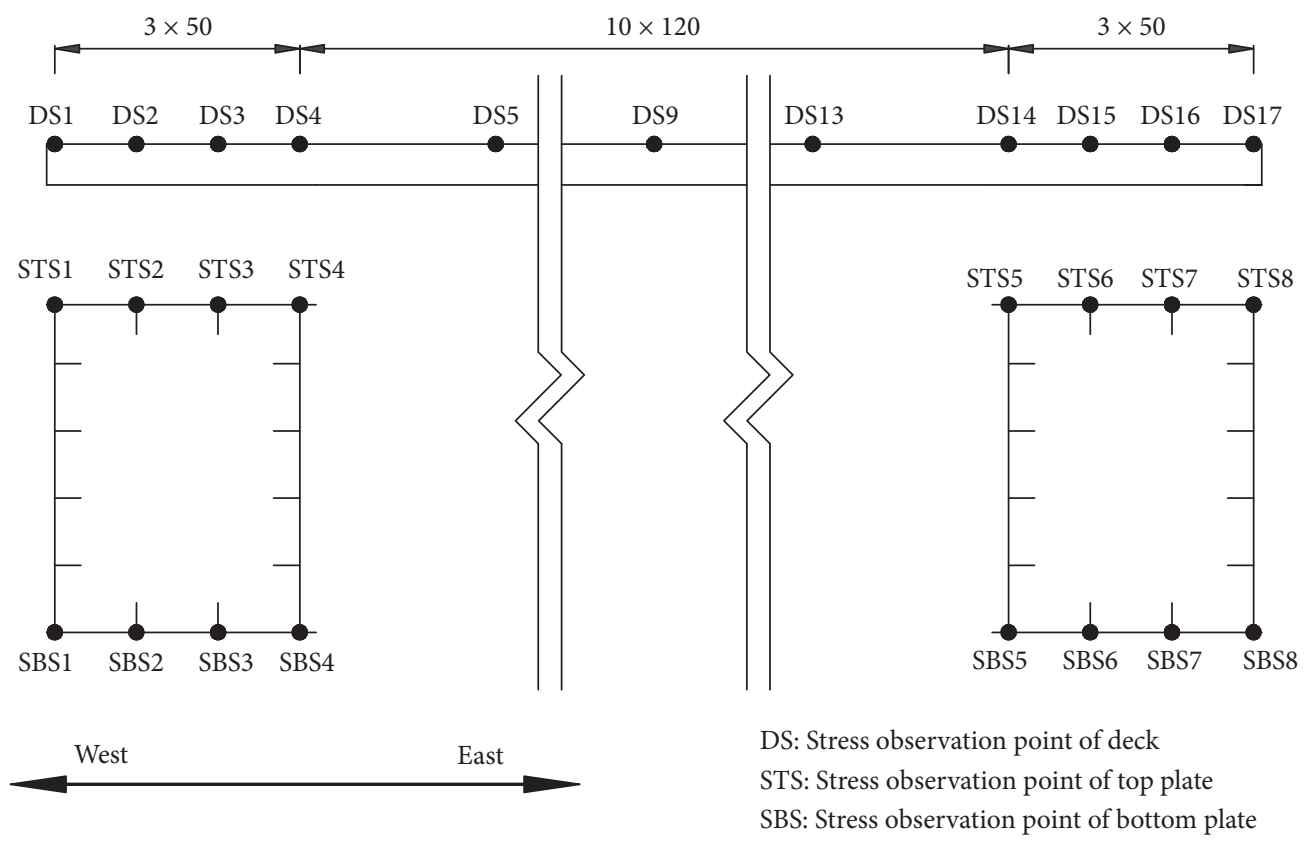

FIGURE 13: The location of stress observation points.

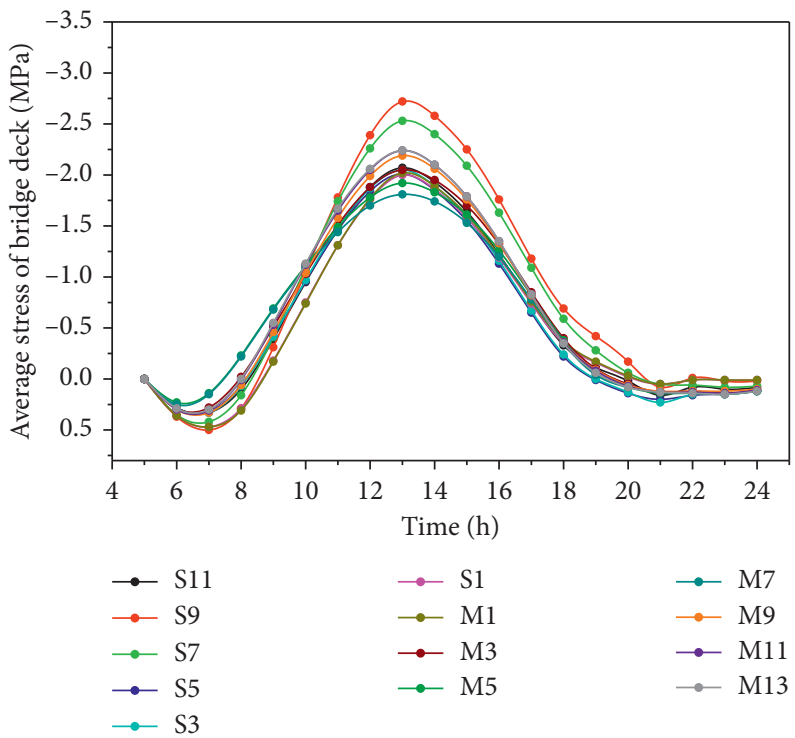

Figure 14: The average value of stress on the upper edge of the cross sections of the bridge deck.

all sections reached the maximum stress at 13 o'clock. The stress distribution (DS1 DS 17) of the upper edge of each section of the bridge deck at 13 o'clock is shown in Figure 15. The compressive stress on the bridge deck near the top plate of the steel box (DS1 DS4 and DS14 DS17) was lower than that on the bridge deck between the two separated steel boxes (DS5 DS13). After 13 o'clock, the stress gradually decreased. The reason for this phenomenon is that the steel boxes heated up faster than the bridge deck, and then, the restraint on the bridge deck was decreased after the steel beam heated up, which reduced the compressive stress on the bridge deck. In summer, the maximum compressive stress on the bridge deck was $3.30 \mathrm{MPa}$, and the stress nonuniform coefficient (maximum value of stress/average of stress) on each section was between 1.15 and 1.32. In winter, the maximum compressive stress on the bridge deck was $2.16 \mathrm{MPa}$, and the stress nonuniform coefficient (maximum value of stress/average of stress) on each section was between 1.30 and 1.41 .

The calculation results of the maximum stress on the bridge deck in both the mixed element model and the beam element model in summer are shown in Figure 16. The maximum values of the stress on each segment of the bridge deck in the mixed element model were all larger than those in the beam element model, and the maximum stress value of the mixed element model was more than 


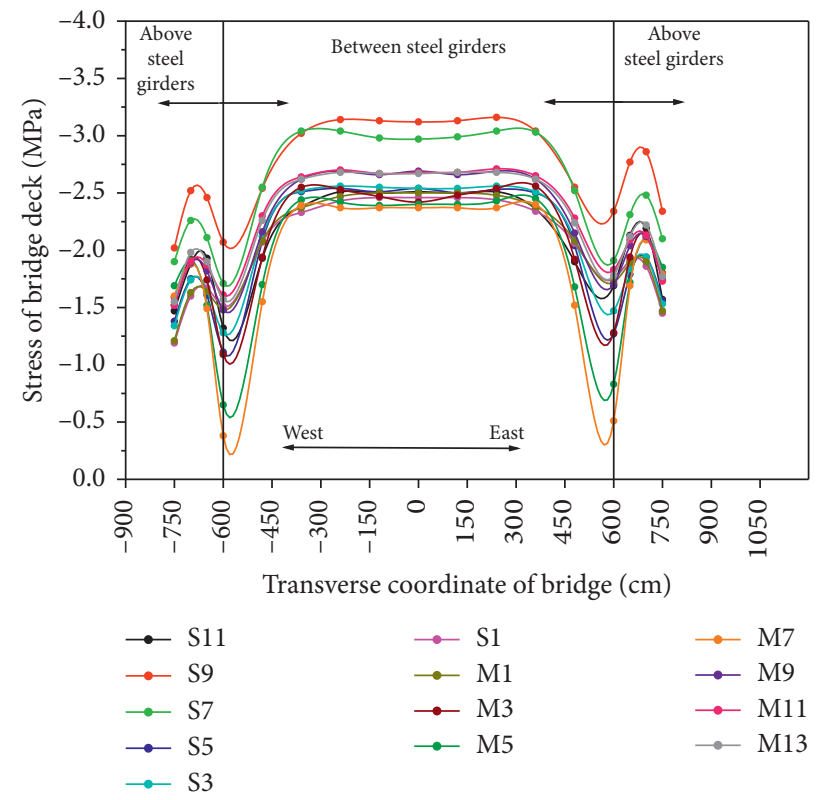

Figure 15: The stress value of the upper edge of each cross section of the bridge deck at 13 o'clock.

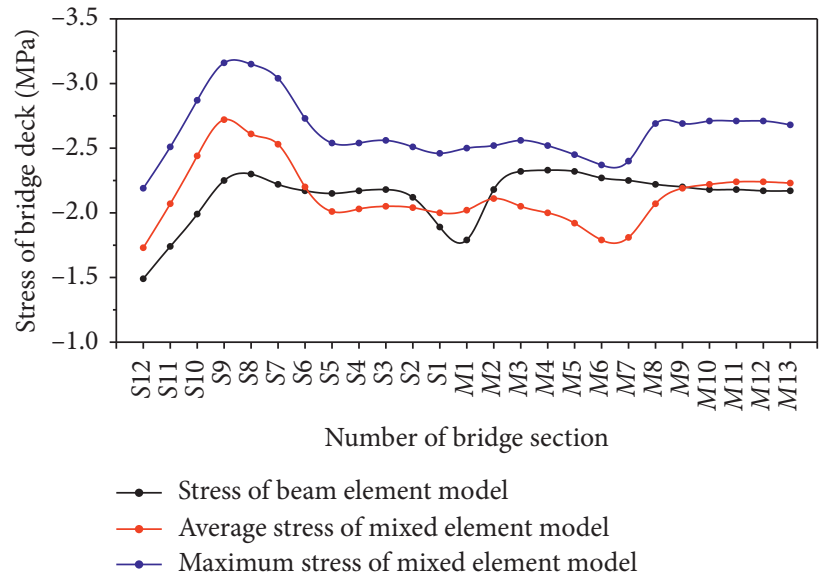

Figure 16: The stress distribution of the upper edge of the cross section of the bridge deck.

$20 \%$ larger than that of the beam element model in most of the segments. This occurred because the stress of the mixed element model reached its maximum at 13 o'clock rather than at 14 o'clock, corresponding to the maximum level of the beam element model. The stress on the bridge deck between the two separated steel boxes was larger than the average stress of the cross section. The mixed element model can incorporate the inhomogeneity of the stress in each section.

6.6. Stress of Top Plate of Steel Box. Taking segments S7 and M13 as examples, the stress variation of the top plate of the steel boxes in summer is shown in Figure 17. In summer, the east side of the web was heated up in the morning; the deformation was restricted at STS8 with relatively high stress, and it then reached the highest temperature at 9 o'clock. The stress gradually decreased as the bridge deck and the top plate of the steel box heated up continuously. The area near the stiffeners of the top plates of the boxes was gradually heated up to the same temperature as the bridge deck. Because the expansion coefficient of steel is greater than that of concrete, the elongation of the stiffeners was restricted, which increased the stress on STS6 and STS7. From 15 o'clock to 18 o'clock, the temperature of these stiffeners began to decrease, but the temperature of the steel girder around the stiffeners decreased much more slowly than that of the bridge deck, which caused the stress to increase continually to the maximum at 18 o'clock. Figure 17 shows that STS2 and STS3 at the west side of the steel girder of the segment M13 reached the maximum stress at this cross section at $19.4 \mathrm{MPa}$ at 17 o'clock. The maximum stress variation of each segment of steel girder in summer is shown in Figure 18. The two stress peaks of the east side of the steel girder correspond to the external web (STS8) and the stiffener (STS6 and STS7), respectively. The stress peak of the 


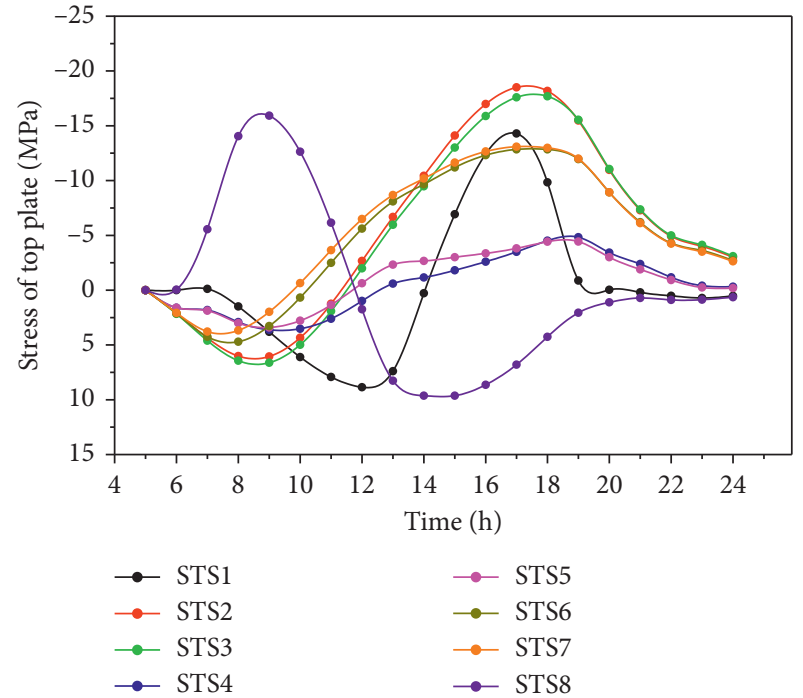

(a)

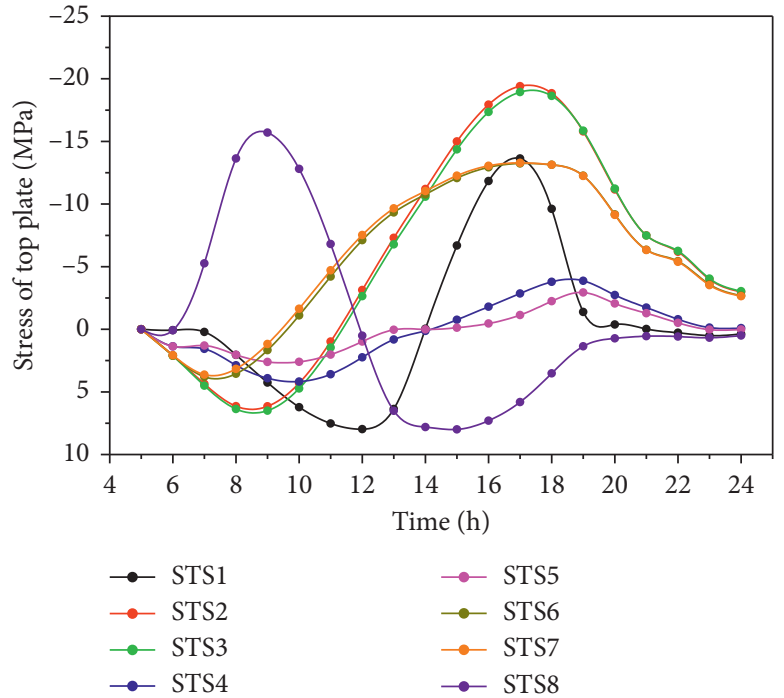

(b)

FIgURE 17: The stress variation of the top plate at segment S7 and segment M13. (a) The stress variation of the top plate at segment S7. (b) The stress variation of the top plate at segment M13.

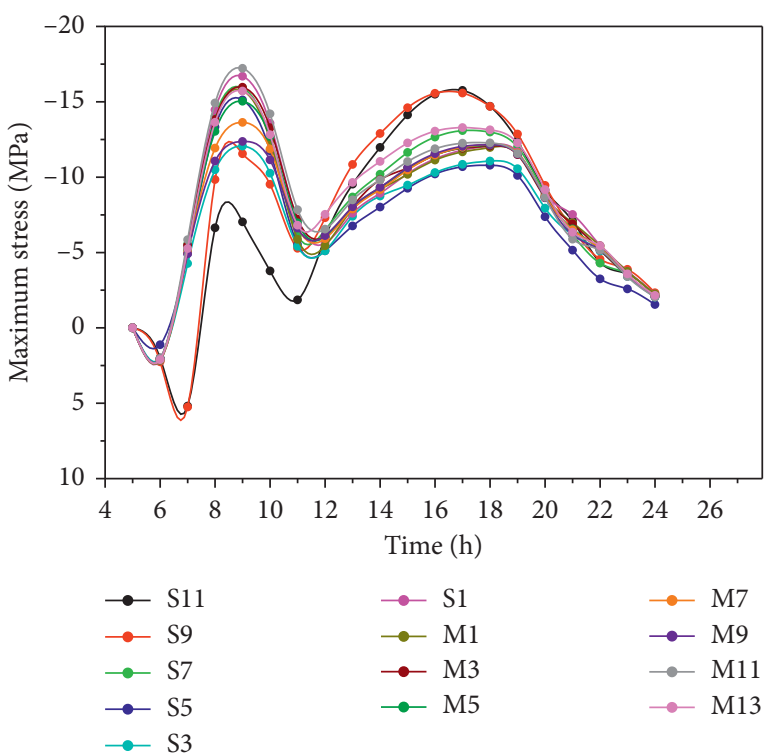

(a)

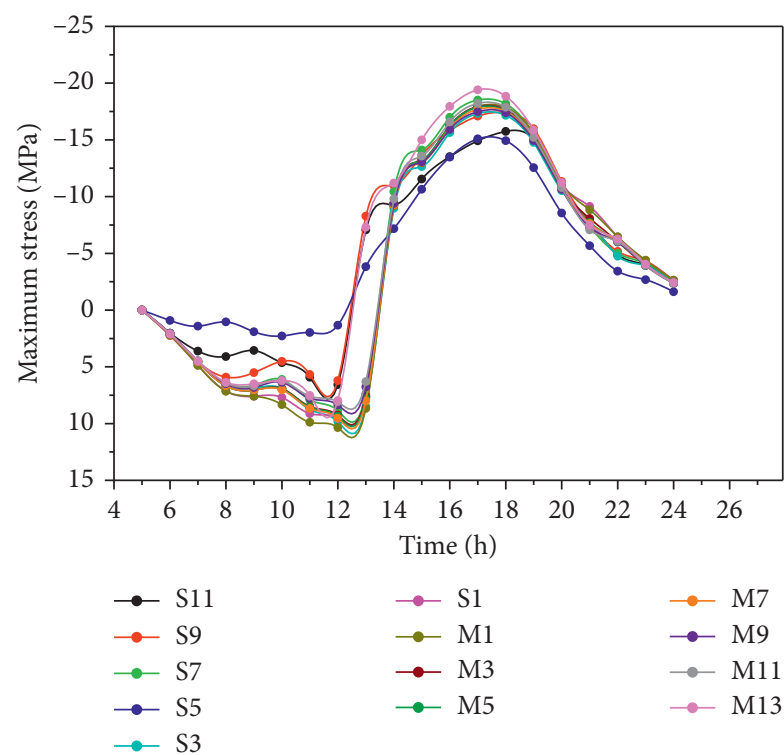

(b)

Figure 18: The maximum stress variation of the top plate of each segment. (a) The maximum stress variation of the top plate of each segment at the west side. (b) The maximum stress variation of the top plate of each segment at the east side.

west side of the steel girder corresponds to the stiffener (STS2 and STS3). In winter, the top plate of the steel girder reached the maximum stress (17 MPa) at 10 o'clock, and the maximum value was located at STS8 of the segment M12.

The calculated maximum stress value of the top plate of the steel girder in both the beam element model and the mixed element model in summer are shown in Figure 19. The maximum thermal stress calculated by the mixed element model was $14.7 \mathrm{MPa}$ higher than that calculated by the beam element model, which was located in segment M13. The reason for this is that the mixed element can take the local thermal effect into account, but the beam element model can only consider the average thermal effect of the entire cross section.

6.7. Stress of the Bottom Plate of the Steel Box. Taking segments as S7 and M13 as examples, the stress variation of the bottom plate of the steel boxes in summer is shown in Figure 20. The exterior web of the east side of the steel girder was heated up rapidly in the morning, which induced relatively high stress because of the deformation restricted at 


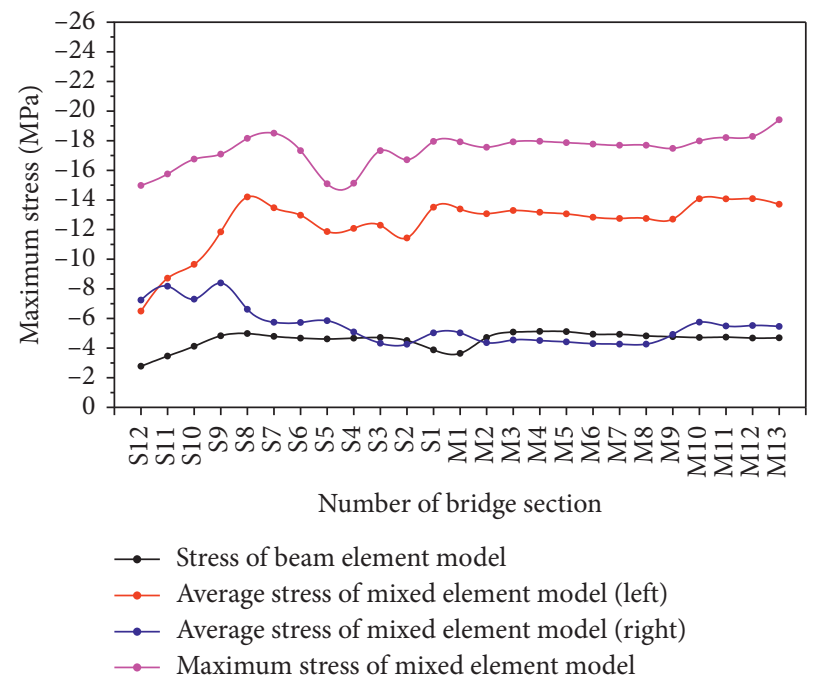

Figure 19: The calculated stress value of the top plate of the steel girder in both the beam element model and the mixed element model in summer.

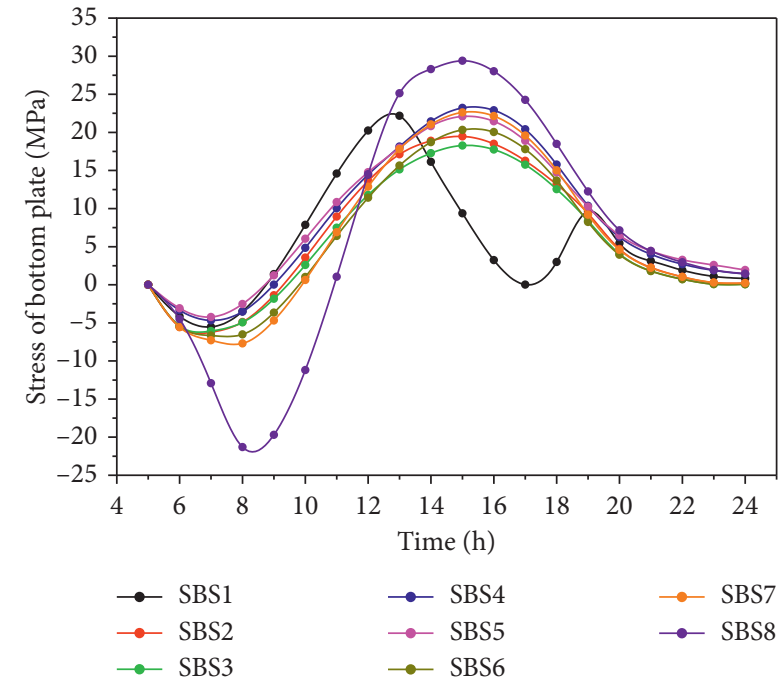

(a)

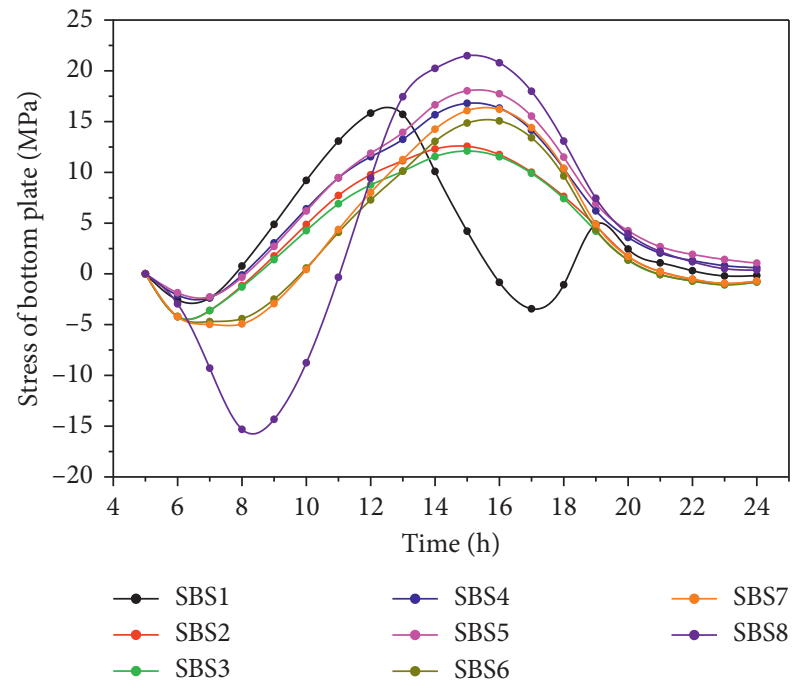

(b)

FIgURE 20: The stress variation of the bottom plate at segment S7 and segment M13. (a) The stress variation of the bottom plate at segment S7. (b) The stress variation of the bottom plate at segment M13.

SBS8. The stress at each of the observation points (SBS1 SBS7) reached the maximum at 15 o'clock. The stress at SBS1 of the exterior web on the west side of the steel girder decreased from 12 o'clock to 17 o'clock. The reason for this is that the exterior web was heated up gradually to offset the thermal tensile stress after noon. The maximum stress variation of the bottom plate of each segment of the steel girder is shown as Figure 21. Figure 21 shows that the maximum stress of the bottom plate $(31 \mathrm{MPa})$ appeared at 15 o'clock, located at SBS8 of segment S7.

The calculated maximum stress values of the bottom plate of the steel girder in both the beam element model and the mixed element model in summer are shown in Figure 22. The average stress and maximum stress of the bottom plate of the steel girder calculated by the mixed element model were both larger than those of the beam element, and the difference of the calculated maximum thermal stress between the two models was larger than 15.9 MPa at segment S7, since the mixed element can take the local thermal effect into account.

6.8. Stress of Interface between Concrete Deck and Steel Boxes. The shear stress and vertical tensile stress of the interface between the concrete deck and the steel boxes reached the maximum at 15 o'clock and 17 o'clock, respectively. The maximum interface shear stress and maximum interface tensile stress on the interface of the main beam are shown in 


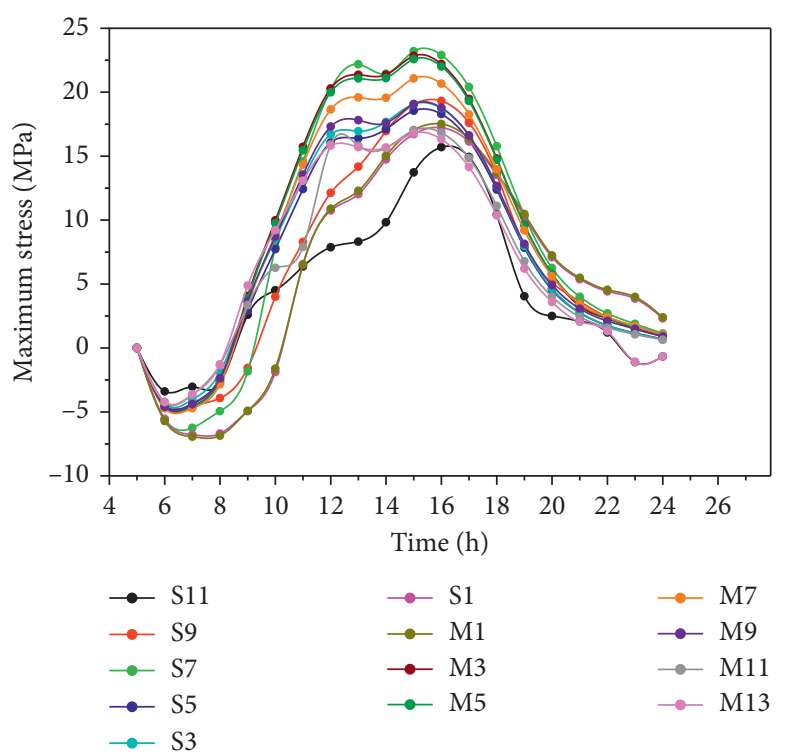

(a)

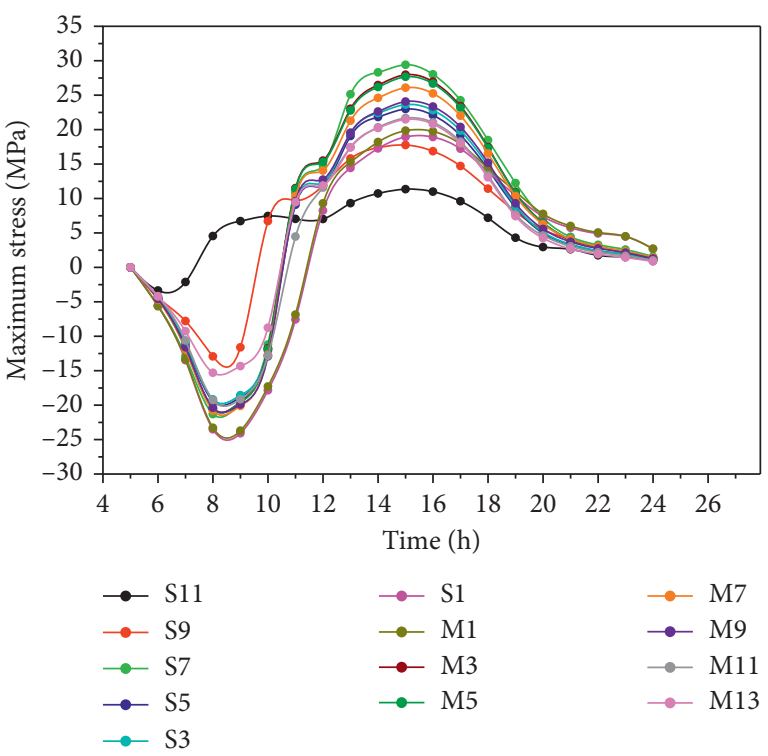

(b)

Figure 21: The maximum stress variation of the bottom plate of each segment. (a) The maximum stress variation of the bottom plate of each segment on the west side. (b) The maximum stress variation of the bottom plate of each segment on the east side.

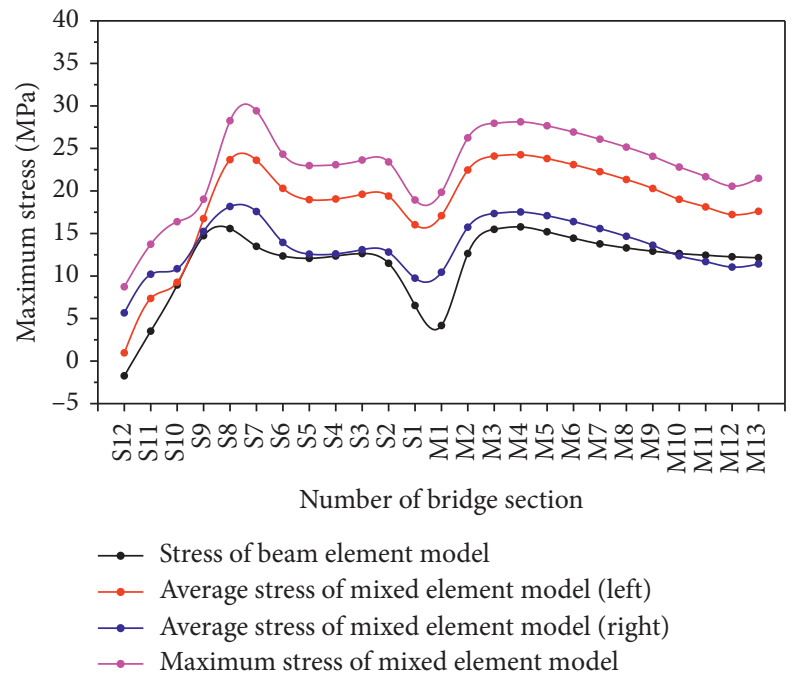

Figure 22: The calculated stress value of the bottom plate of the steel girder in both the beam element model and the mixed element model in summer.

Figures 23 and 24. The maximum shear stress on the interface was about $0.25 \mathrm{MPa}$, which appeared near the interface position corresponding to the beam (the beam corresponding to the anchorage cable), namely, position 2 in Figure 25. The maximum tensile stress on the interface was about $0.68-0.74 \mathrm{MPa}$, which appeared at the interface position corresponding to the beam (the beam corresponding to the anchorage cable), namely, position 2 in Figure 25. The position where the second largest stress occurred was the corresponding section position of the other beams (i.e., positions 1 and 3 in Figure 25), and the value of the tensile stress was about $0.51-0.60 \mathrm{MPa}$. The times when the maximum shear stress and the maximum tensile stress appeared on the interface of the main beam were not identical, and they were not at the 14 o' clock time that corresponds with the maximum temperature gradient of the section. 


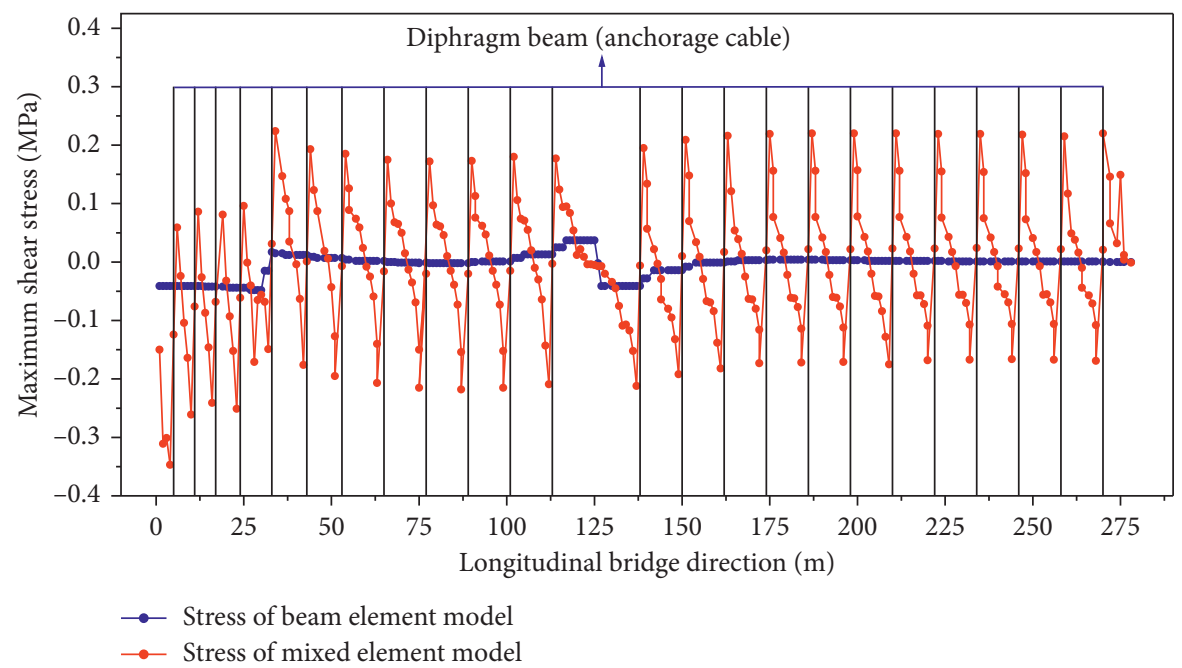

FIGURE 23: The maximum shear stress of the interface between the concrete deck and the steel boxes corresponding to each segment of the main girder at 15 o'clock.

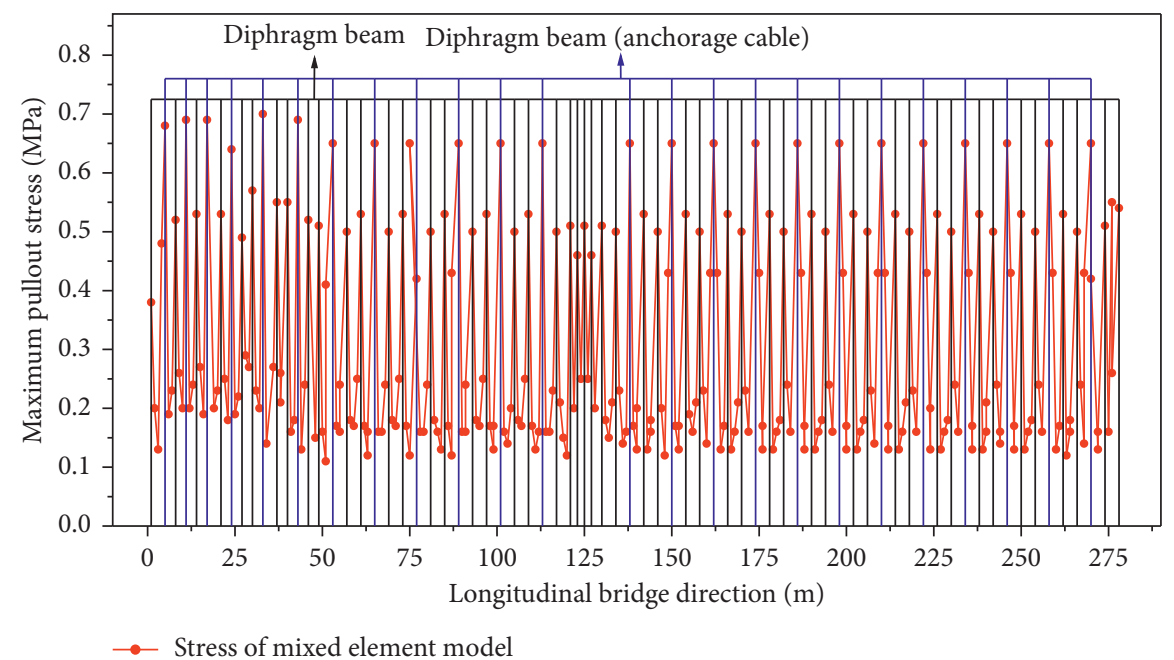

FIGURE 24: The maximum vertical tensile stress of the interface between the concrete deck and the steel boxes corresponding to each segment of the main girder at 17 o'clock.

Standard segment $i, i+1, i+2$

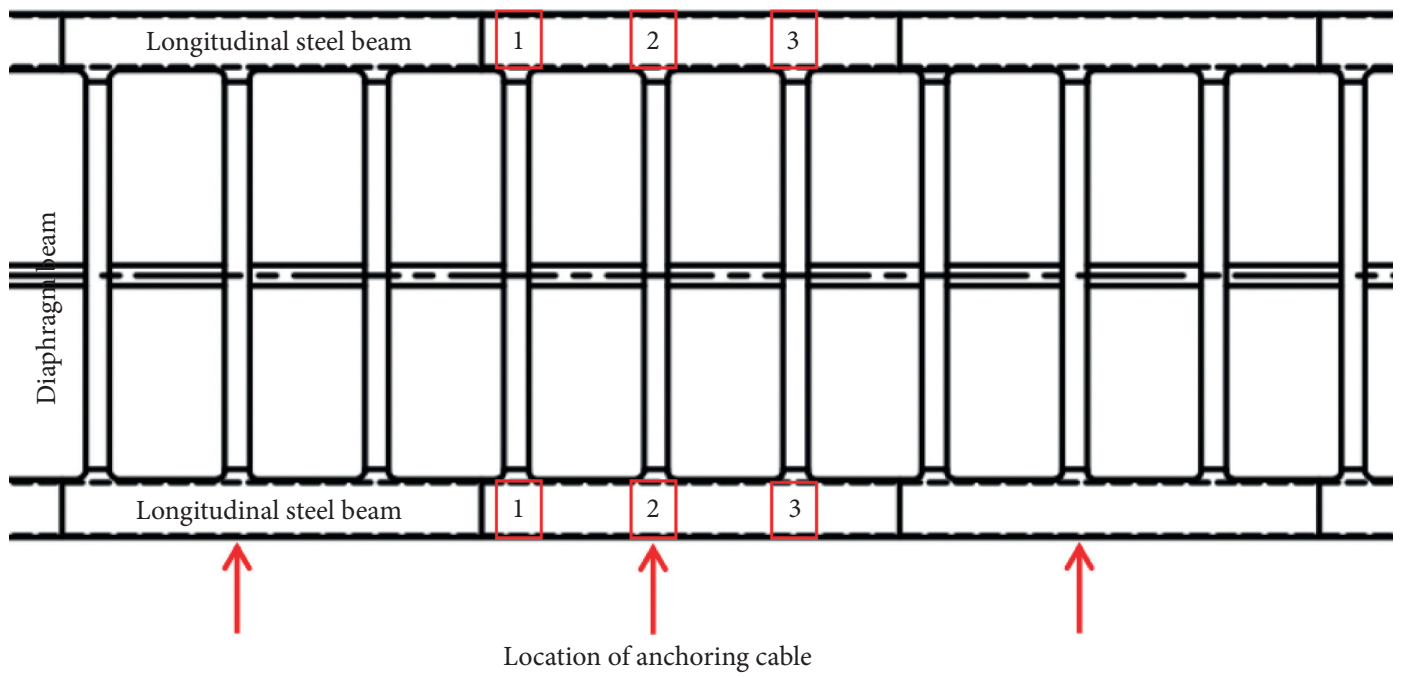

FIGURE 25: Diagram of the maximum interfacial stress position. 


\section{Conclusions}

In this paper, the thermal effect of a separated double-sided box steel-concrete composite girder cable-stayed bridge under solar radiation is analyzed by comparing the calculation results of the mixed element model and the beam element model (using the maximum temperature gradient). The following conclusions can be drawn from this technical application and results analysis:

(1) The thermal field distribution of each component section of the separated double-sided box steelconcrete composite girder cable-stayed bridge under solar radiation is affected by multiple factors, such as ambient temperature, solar azimuth angle and elevation angle, and field wind speed. It is inaccurate to describe the real cross-section thermal field by means of a traditional one-dimensional temperature distribution model. Moreover, the mechanical effect under solar radiation is complex, so the mixed element model, rather than the beam element model, should be used for detailed analysis because the beam element model will underestimate the thermal effect.

(2) The temperature stress distribution on the bridge deck is not uniform. In summer, the maximum temperature stress on the bridge deck is $3.3 \mathrm{MPa}$, and the stress nonuniformity coefficient of the bridge deck in each section is between 1.15 and 1.32. In addition, the calculation results of the mixed element model are generally $20 \%$ larger than those of the beam element model.

(3) The temperature stress of the steel box girder is greatly affected by direct solar radiation. In summer, the maximum temperature stress on the steel box girder is $31 \mathrm{MPa}$, and the maximum difference between the maximum temperature stress on the steel beam calculated by the mixed element model and that calculated by the beam element model is 15.9 $\mathrm{MPa}$.

(4) From the calculation results of the mixed element model, it can be seen that the shear studs at the interface near the beam (the beam corresponding to the anchorage of the stay cable) should first be increased in the separated bilateral box steel-concrete composite girder cable-stayed bridge, and then, the shear studs at the interface near the remaining beams should be increased.

(5) For the same season, the time when each component (bridge deck, steel beams, and girder interface) reaches the maximum stress is not completely consistent with the time when the maximum temperature gradient of each section occurs. Adopting only the maximum thermal field (temperature gradient) of the section for structural thermal analysis will underestimate the temperature stress value of the components.

(6) Because a temperature monitoring system has not been installed in the project, the actual meteorological data and the temperature stress data of the bridge cannot be obtained. Therefore, this paper mainly analyses and draws conclusions based on the numerical calculation results. The numerical results of this paper still need to be verified by means of field monitoring data. Using the monitoring data to verify and modify the finite element calculation model has research value, and this further step will be pursued in the future research.

\section{Data Availability}

The data used to support the findings of the study are available from the corresponding author upon request.

\section{Conflicts of Interest}

The authors declare that they have no conflicts of interest regarding the publication of this paper.

\section{Acknowledgments}

The help of engineers and technicians in the Key Laboratory of Bridge Detection Reinforcement Technology Ministry of Communications of Chang'an University is highly appreciated. These supports are gratefully acknowledged. The authors gratefully acknowledge the financial support of the Natural Science Basic Research Program of Shaanxi (Program 2020JQ-377) and the Special Funds for Fundamental Research Business Fees of Central Universities of Chang'an University (Program 310821161012).

\section{References}

[1] S. L. Liu and S. S. Wang, Design of Cable-stayed Bridge, pp. 310-314, People's Communications Press, Beijing, China, 2006.

[2] A. Barbaros and A. Sevket, "Construction stage analysis of three-dimensional cable-stayed bridges," Steel and Composite Structures, vol. 12, no. 5, pp. 413-426, 2012.

[3] J. Liu, Y. Liu, L. Jiang, and N. Zhang, "Long-term field test of temperature gradients on the composite girder of a long-span cable-stayed bridge," Advances in Structural Engineering, vol. 22, no. 13, pp. 2785-2798, 2019.

[4] A. A. Mosavi, R. Seracino, and S. Rizkalla, "Effect of temperature on daily modal variability of a steel-concrete composite bridge," Journal of Bridge Engineering, vol. 17, no. 6, pp. 979-983, 2012.

[5] Y. C. Zhou, S. N. Hu, and L. Song, "Effect analysis of steelconcrete composite beam caused by sudden change of temperature," Journal of Traffic and Transportation Engineering, vol. 13, no. 1, pp. 20-26, 2013.

[6] Z. Y. Wang, Temperature Effect of Steel-Concrete Composite Cable-Stayed Bridge during the Construction Phase in ArcticAlpine Region, pp. 46-54, Chang'an University, Xi'an, China, 2017.

[7] J. S. Zhu and J. L. Meng, "Effective and fine analysis for temperature effect of bridges in natural environments," Journal of Bridge Engineering, vol. 22, no. 6, Article ID 04017017, 2017.

[8] W. H. Dilger, A. Ghali, M. Chan, M. S. Cheung, and M. A. Maes, "Temperature stresses in composite box girder 
bridges," Journal of Structural Engineering, vol. 109, no. 6, pp. 1460-1478, 1983.

[9] Y. J. Liu and J. Liu, "Review on solar thermal actions of bridge structures," China Civil Engineering Journal, vol. 52, no. 5, pp. 59-78, 2019.

[10] J. Liu, Y. J. Liu, and S. F. Stiemer, "Vertical temperature gradient pattern of “上”-shape steel-concrete composite girder in arctic-alpine region," Journal of Traffic and Transportation Engineering, vol. 17, no. 4, pp. 32-44, 2017.

[11] D. J. Ji and Y. J. Liu, "Temperature effect analysis of steelconcrete composite girder cable-stayed bridge in arctic-alpine region," Journal of Architecture Structures Civil Engineering, vol. 33, no. 1, pp. 113-119, 2016.

[12] L. E. Rodrigue, P. J. Barr, and M. W. Halling, "Temperature effects on a box-girder integral-abutment bridge," Structural Control \& Health Monitoring, vol. 28, no. 3, pp. 583-591, 2014.

[13] M. M. Elbadry and A. Ghali, "Temperature variations in concrete bridges," Journal of Structural Engineering, vol. 109, no. 10 , pp. 2355-2374, 1983.

[14] F. Kehlbeck, Effect of Solar Radiation on the Bridge Structure, pp. 103-107, China Railway Press, Beijing, China, 1981.

[15] Y. Xia, B. Chen, X.-q. Zhou, and Y.-l. Xu, "Field monitoring and numerical analysis of Tsing Ma Suspension Bridge temperature behavior," Structural Control and Health Monitoring, vol. 20, no. 4, pp. 560-575, 2013.

[16] W. Robert, Y. K. Ki, and B. James, "Effect of solar radiation on suspension bridge performance," Journal of Traffic and Transportation Engineering, vol. 20, no. 5, Article ID 04014077, 2015.

[17] O. Larsson and S. Thelandersson, "Estimating extreme values of thermal gradients in concrete structures," Materials and Structures, vol. 44, no. 8, pp. 1491-1500, 2011.

[18] L. R. Zhou, Y. Xia, and J. M. W. Brownjohn, "Temperature analysis of a long-span suspension bridge based on field monitoring and numerical simulation," Journal of Bridge Engineering, vol. 21, no. 1, Article ID 04015027, 2016.

[19] M. Hani and X. M. Song, "Effects of solar temperature gradient on long-span concrete box girder during cantilever construction," Journal of Bridge Engineering, vol. 21, no. 3, Article ID 04015061, 2016.

[20] Y. H. Cao, Y. Jinsuk, and Y. Zhao, "Temperature effects on cable stayed bridge using health monitoring system: a case study," Structural Health Monitoring, vol. 10, no. 5, pp. 1-15, 2010.

[21] N. Taysi and S. Abid, "Temperature distributions and variations in concrete box-girder bridges: experimental and finite element parametric studies," Advances in Structural Engineering, vol. 18, no. 4, pp. 469-486, 2015.

[22] Z. G. Huang, "Field Monitoring and Numerical Analysis on the Temperature of Long-Span Suspension Bridge, pp. 74-97, South China University of Technology, Guangzhou, China, 2016.

[23] People's Communications Press, Specifications for Design of Highway Reinforced Concrete and Prestressed Concrete Bridges and Culverts (JTG 3362-2018), pp. 10-12, People's Communications Press, Beijing, China, 2018.

[24] People's Communications Press, Specification for Design and Construction of Highway Steel-Concrete Composite Bridge (JTG/T D64-01-2015), p. 30, People's Communications Press, Beijing, China, 2015.

[25] Y. D. Du, H. Q. Mao, and A. Q. Liu, "The climatological calculation and distributive character of global solar radiation in Guangdong province," Resources Science, vol. 25, no. 6, pp. 66-70, 2003. 